\title{
Brioflora (Bryophyta e Marchantiophyta) da Ilha do Combu, Belém, PA, Brasil
}

\author{
Osvanda Silva de Moura ${ }^{1}$, Anna Luiza Ilkiu-Borges ${ }^{2,3}$ e Eliete da Silva Brito ${ }^{2}$
}

Recebido: 1.08.2012; aceito: 7.02.2013

\begin{abstract}
Bryoflora (Bryophyta and Marchantiophyta) of Combu Island, Belém, Pará State, Brazil). There are a few studies on bryophytes from Brazilian Islands. Most of these studies are concentrated in the States of São Paulo and Pará. From the latter state, the Islands of Marajó, Germoplasma (in the Tucuruí dam reservoir), Algodoal-Maiandeua, and Trambioca were previously. However, considering the insular region of Belém municipality by itself, there are 39 Islands, including Combu Island, which is under environmental protection. It is formed essentially by várzea forest, one of the main types of floodplain Amazonian forests. The aim of this study was to investigate the bryoflora of Combu Island, Belém, Pará State, through species richness and record numbers of mosses and liverworts, by supplying data about the ecology and geographic distribution of the species in Brazil, besides the morphological and taxonomical comments, when necessary. The collections were carried out in 17 plots of $10 \times 10 \mathrm{~m}$, being nine in high várzea and eight in low várzea. In total, 72 species were identified ( 27 mosses and 45 liverworts). Lejeuneaceae was the most representative family with 41 species. Higher species richness and record number ware observed in high várzea.
\end{abstract}

Key words: fluvial Island, liverworts, mosses, várzea

RESUMO - (Brioflora (Bryophyta e Marchantiophyta) da Ilha do Combu, Belém, PA, Brasil). Somam-se poucos trabalhos com briófitas realizados em ilhas no Brasil. A maioria dos estudos em ilhas está concentrada no Estado de São Paulo e no Pará, no qual foram estudadas as Ilhas do Marajó, Germoplasma (no reservatório de Tucuruí), Algodoal-Maiandeua e Trambioca. Todavia, somente a região insular do município de Belém totaliza 39 ilhas, dentre as quais figura a Ilha do Combu, a qual é uma Área de Proteção Ambiental essencialmente formada por floresta de várzea, um dos principais tipos de florestas inundáveis amazônicas. O objetivo deste estudo foi investigar a brioflora da Ilha do Combu, Belém, PA, através da riqueza e o número de ocorrência de musgos e hepáticas, fornecendo dados sobre a ecologia e distribuição geográfica das espécies no Brasil, além de comentários morfológicos e taxonômicos, quando necessários. As coletas foram realizadas em 17 parcelas de $10 \times 10 \mathrm{~m}$, sendo nove em várzea alta e oito em várzea baixa. No total, foram identificadas 72 espécies (27 musgos e 45 hepáticas). Lejeuneaceae foi a família mais representativa com 41 espécies. Foi observada maior riqueza e número de ocorrência de espécies em várzea alta.

Palavras-chave: hepáticas, ilha fluvial, musgos, várzea

\section{Introdução}

No Brasil, os estudos de briófitas em ilhas ainda são pouco difundidos (Yano \& Peralta 2007a). Entre os trabalhos realizados em ilhas no Brasil estão dois realizados na Ilha de Fernando de Noronha, PE (Gepp 1891, Vital et al. 1991): um em Trindade e Arquipélago de Martins Vaz, RJ (Yano 1998); dois na Ilha de Maracá, RR (Milliken \& Ratter 1989, Yano 1992); dois no RJ, na Ilha Grande e Reserva Ecológica de Rio das Pedras (Oliveira-e-Silva \& Yano 2000, Oliveira-e-Silva et al. 2002); seis trabalhos realizados em nove ilhas costeiras ou continentais no Estado de São Paulo (Yano 1990, Visnadi \& Vital 2001, Yano et al. 2003, Joyce et al. 2006, Peralta \& Yano 2008, Yano \& Peralta 2008a); e sete realizados em quatro ilhas no Estado do Pará (Lisboa \& Maciel 1994, Lisboa et al. 1998, 1999, IlkiuBorges et al. 2004, 2009, Souza \& Lisboa 2005).

1. Parte da Dissertação de Mestrado da primeira Autora, Programa de Pós-Graduação em Ciências Biológicas-Mestrado em Botânica Tropical, Universidade Federal Rural da Amazônia/ Museu Paraense Emílio Goeldi

2. Museu Paraense Emílio Goeldi, Coordenação de Botânica, Av. Perimetral 1901, Terra Firme, 66077-530 Belém, PA, Brasil

3. Autor para correspondência: ilkiuborges@yahoo.com.br 
Os primeiros estudos sobre a brioflora insular no Estado do Pará foram realizados na Ilha do Marajó. Todavia, nesses estudos foram tratados apenas os musgos (Lisboa \& Maciel 1994, Lisboa et al. 1998, 1999). Recentemente, em um estudo realizado por Brito (2011), além dos musgos, foram incluídas as hepáticas de dois municípios da Ilha do Marajó, das quais uma espécie era uma nova ocorrência para a América do Sul (Brito \& Ilkiu-Borges 2012).

A partir de 2000, outras ilhas do Pará tiveram sua brioflora estudada e a maioria desses estudos também incluiram as duas divisões. Na Ilha de Germoplasma (ilha fluvial artificial), Ilkiu-Borges et al. (2004) identificaram 25 espécies (13 hepáticas e 12 musgos) e na Ilha de Algodoal-Maiandeua (ilha marinha), Ilkiu-Borges et al. (2009) obtiveram um total de 14 espécies ( 8 hepáticas e 6 musgos). Na Ilha de Trambioca (ilha fluvial), foram estudados somente os musgos (40 espécies), por Souza \& Lisboa (2005).

O estuário amazônico tem sua geografia marcada pela grande concentração de ilhas. Somente a região insular do município de Belém totaliza 39 ilhas (Gregório 2008), dentre as quais figura a Ilha do Combu, uma ilha continental fluvial. Entre as outras ilhas, essa destaca-se por ser Área de Proteção Ambiental, a qual é essencialmente formada por floresta de várzea, um dos principais tipos de florestas inundáveis amazônicas. Esses tipos de florestas ocupam cerca de $98.000 \mathrm{~km}^{2}$ da Amazônia, dos quais $76.000 \mathrm{~km}^{2}$ representam as várzeas (Araújo et al. 1986), ou seja, 1,6 \% da superfície da Amazônia brasileira.

As florestas de várzea são ambientes periodicamente inundados, influenciados pelos regimes de marés, apresentando períodos de enchentes e vazantes, que provocam variação constante no ambiente. São ambientes frágeis, com origem e funcionamento ligados à deposição de sedimentos geologicamente recentes (Queiroz et al. 2007).

As várzeas são exploradas de diversas formas, principalmente através do extrativismo vegetal (Anderson \& Jardim 1989, Anderson \& Ioris 1992) como do açaí (palmito e fruto), seringa, andiroba e madeira. Em alguns locais, as várzeas são utilizadas para a pecuária extensiva (AMAPÁ 2000) e também apresentam grande potencial para agricultura (Ribeiro et al. 2004). Por serem ambientes de grande potencial econômico, tradicionalmente utilizado pelos povos amazônicos, correm maior risco de degradação especialmente com a proximidade de centros urbanos.
As influências sedimentares e topográficas causam efeitos importantes na estrutura da vegetação, condicionando a formação de dois ambientes topográficos de várzea, várzea alta e várzea baixa e, por conseguinte, determinando diversidade florística diferente (Hamp 1991 apud Jardim \& Vieira 2001). Assim, a várzea baixa é constituída por palmeiras, possui menor diversidade em espécies arbóreas florestais e o solo permanece temporariamente alagado (Jardim \& Vieira 2001). Na várzea alta são encontradas espécies arbóreas com maior frequência, além de palmeiras, e o solo possui pouca influência hídrica (Pires 1974, Jardim \& Vieira 2001).

Este trabalho tem como objetivo avaliar a brioflora da Ilha do Combu, município de Belém, PA, Brasil, através da riqueza e do número de ocorrência de musgos e hepáticas, fornecendo dados sobre a ecologia e a distribuição geográfica das espécies no Brasil, além de comentários morfológicos e taxonômicos, quando necessários.

\section{Material e métodos}

A Ilha do Combu constitui uma Área de Proteção Ambiental (APA) com o mesmo nome, instituída a partir da Lei Estadual ${ }^{\circ} 6.083$ de 13 de novembro de 1997. A ilha está localizada no município de Belém, Estado do Pará, na margem esquerda do rio Guamá, a $1,5 \mathrm{~km}$ de distância da cidade de Belém por via fluvial. Abrange área total de aproximadamente $15 \mathrm{~km}^{2}$ posicionada geograficamente a $48^{\circ} 25^{\prime} \mathrm{S}$ e $1^{\circ} 25^{\prime} \mathrm{W}$. O clima é do tipo Am, segundo a classificação de Köppen; pluviosidade com média anual de $2.500 \mathrm{~mm}$ e temperatura média anual de $27{ }^{\circ} \mathrm{C}$ (Jardim \& Vieira 2001).

A vegetação da Ilha do Combu é composta por floresta de várzea com cipós, árvores, arbustos e espécies de subosque, apresentando estrutura e composição florística variada, incluindo florestas primária e secundária (Rodrigues et al. 2006).

Foram realizadas cinco excursões, no período de agosto a setembro de 2008, com a duração de um dia cada. As amostras foram coletadas em 17 parcelas de $10 \times 10 \mathrm{~m}$, sendo nove na parte interna da ilha, em ambiente de floresta de várzea alta (FVA), próximo ao Furo do Combu; e oito no lado leste da ilha, em ambiente de floresta de várzea baixa (FVB), próximo ao Furo da Paciência (figura 1). A coleta foi realizada em toda a área das parcelas. A adoção de parcelas teve o intuito de não tendenciar a coleta de amostras mais vistosas ou vigorosas. 
A coleta de material seguiu Lisboa (1993) e o material coletado foi transportado para o Laboratório de Briologia do Museu Paraense Emílio Goeldi, onde foi seco ao sol.

As espécies foram classificadas segundo Robbins (1952), de acordo com o tipo de substrato em que foram coletadas. As espécies que ocorreram sobre termiteiros foram classificadas à parte, por não se enquadrarem nas demais categorias.

A identificação dos táxons foi baseada em Lisboa (1993), Gradstein (1994), Reiner-Drehwald (2000, 2007), Buck (2003), Dauphin (2003), Gradstein \& Costa (2003), Zartman \& Ilkiu-Borges (2007) e Gradstein \& Ilkiu-Borges (2009). Lejeunea obidensis Spruce foi identificada pela Dra. Maria Elena Reiner-Drehwald, do Albrecht-von-Haller-Institut, Alemanha. Para a distribuição geográfica dos táxons, foram consultados os trabalhos de Gradstein \& Costa (2003), Yano (2006, 2008), Yano \& Peralta (2007b, 2008b), Zartman \& Ilkiu-Borges (2007), e a Lista de Espécies da Flora do Brasil (2012). Eventualmente, foram utilizados trabalhos específicos, os quais serão citados ao longo do texto.

Os sistemas de classificação adotados neste trabalho foram os propostos por Crandald-Stotler et al. (2009) para Marchantiophyta e Goffinet et al. (2009) para Bryophyta.

Todas as amostras coletadas estão depositadas no Herbário João Murça Pires (MG) do Museu Paraense Emílio Goeldi, Belém, PA, Brasil.

\section{Resultados e Discussão}

Foram observadas 1.088 ocorrências de briófitas (231 musgos e 857 hepáticas), que correspondem a 72 espécies, sendo 27 musgos e 45 hepáticas (tabela 1).

As espécies de musgos estão distribuídas em 15 gêneros e oito famílias, das quais as mais representativas foram Pilotrichaceae, Calymperaceae e Sematophyllaceae (tabela 1). Geralmente, Calymperaceae e Fissidentaceae estão entre as famílias mais ricas e abundantes em florestas de planície na região neotropical; mas Pilotrichaceae e Sematophyllaceae também estão entre as mais diversas (Gradstein et al. 2001). Pilotrichaceae é, particularmente, rica em número de espécies restritas ao Neotrópico (Gradstein et al. 2001), e na Ilha do Combu, a referida família está representada por três gêneros, Crossomitrium Müll. Hal., Lepidopilium (Brid.) Brid. e Pilotrichum P. Beauv., com uma espécie cada.
Neste trabalho, Calymperes palisotii foi a espécie de musgo mais frequente, corroborando os resultados encontrados por Lisboa et al. (1998), seguida de Callicostella pallida (Hornsch.) Ångstr., Fissidens guianensis Mont., Neckeropsis disticha (Hedwig) Kindberg, Isopterygium tenerum (Sw.) Mitt., F. hornschuchii Mont. e Calymperes afzelii Sw. As referidas espécies foram encontradas em ambos os tipos de floresta, mas na várzea alta o número de ocorrências foi constantemente maior (tabela 1).

As 45 espécies de hepáticas identificadas estão distribuídas em 17 gêneros e três famílias. Repetindo o que costuma ocorrer em inventários de briófitas na Amazônia, Lejeuneaceae destacou-se como a família mais diversa e frequente (41 spp.), seguida de Plagiochilaceae e Radulaceae (2 spp. cada) (tabela 1). Plagiochilaceae seria a terceira em ordem de importância nesta região, após Lepidoziaceae (Gradstein \& Pócs 1989), entretanto, Lepidoziaceae não foi coletada na Ilha do Combu, mostrando que sua presença é menos comum em inventários no Baixo Amazonas, estando mais bem representada na Amazônia Central (Gradstein \& Costa 2003).

Stictolejeunea squamata (Willd. ex Weber) Schiffn. foi a hepática que se destacou como a mais frequente na Ilha do Combu, seguida de Ceratolejeunea cornuta (Lindenb.) Schiffn., Symbiezidium barbiflorum (Lindenb. \& Gottsche) A. Evans, Rectolejeunea berteroana (Gottsche ex Steph.) A. Evans, C. coarina (Gottsche) Steph., Radula javanica Gottsche e Stictolejeunea balfourii (Mitt.) E.W. Jones (tabela 1).

Das 45 espécies de hepáticas identificadas, 18 apresentaram lóbulos exclusivamente ou frequentemente reduzidos: Ceratolejeunea coarina (Gottsche) Steph., C. cornuta, C. cubensis (Mont.) Schiffn., Cheilolejeunea adnata (Kunze) Grolle, C. discoidea (Lehm. \& Lindenb.) Kachr. \& R.M. Schust., C. rigidula (Mont.) R.M. Schust., Cololejeunea camillii (Lehm.) A. Evans, C. cardiocarpa (Mont.) A. Evans, C. contractiloba A. Evans, Lejeunea adpressa Nees, L. combuensis O.S. Moura, Ilk.-Borg. \& M.E. Reiner, L. controversa Gottsche, L. laetevirens Nees \& Mont., L.phyllobola Nees \& Mont., Microlejeunea epiphylla Bischl., Rectolejeunea berteroana Gottsche ex Steph.) A. Evans, R. emarginuliflora (Gottsche) A. Evans e Symbiezidium barbiflorum (Lindenb. \& Gottsche) A. Evans. Essa pode ser uma resposta morfológica às condições de elevada umidade, características do ecossistema de várzea. Lóbulos 
muito pequenos são geralmente característicos de espécies típicas de florestas úmidas tropicais, enquanto lóbulos grandes caracterizam espécies de locais abertos e secos (Gradstein 1994). Cornelissen \& ter Steege (1989), ao compararem espécimes de Symbiezidium barbiflorum que cresciam na copa e no subosque de uma floresta tropical, observaram que os espécimes de copa apresentavam lóbulos bem maiores do que os de subosque, onde há maior concentração de umidade.

Observou-se que a riqueza e o número de ocorrências de briófitas na Ilha do Combu foram maiores na floresta de várzea alta do que na floresta de várzea baixa (figura 2). Esses resultados podem estar relacionados à maior riqueza de espécies arbóreas e menor representatividade de palmeiras na várzea alta do Combu (Pires 1974, Jardim \& Vieira 2001), o que propicia um ambiente mais sombreado para a brioflora. Na várzea baixa da Ilha do Combu, as palmeiras são mais representativas (Jardim \& Vieira 2001), resultando em ambiente mais aberto, expondo a brioflora a intensa luz solar.

Com relação ao número de espécies, as hepáticas predominaram tanto em floresta de várzea alta (42 spp.) quanto de várzea baixa (33 spp.), se comparadas aos musgos (24 spp. e 16 spp., respectivamente) (figura 2).

Das 72 espécies identificadas, uma espécie e uma variedade são novas ocorrências para o Estado do Pará, Lepidopilum affine Müll. Hal. e Cololejeunea microscopica var. exigua (A. Evans) Lücking \& Pócs. Crossomitrium epiphyllum foi coletada pela primeira vez na região Norte do Brasil. Durante este estudo foi coletada uma espécie nova para a ciência, Lejeunea combuensis O.S. Moura, Ilk.-Borg. \& M.E. Reiner, descrita por Moura et al. (2012).

Das espécies identificadas, a maioria é corticícola, seguida de epíxilas e epífilas. Contudo, a maioria

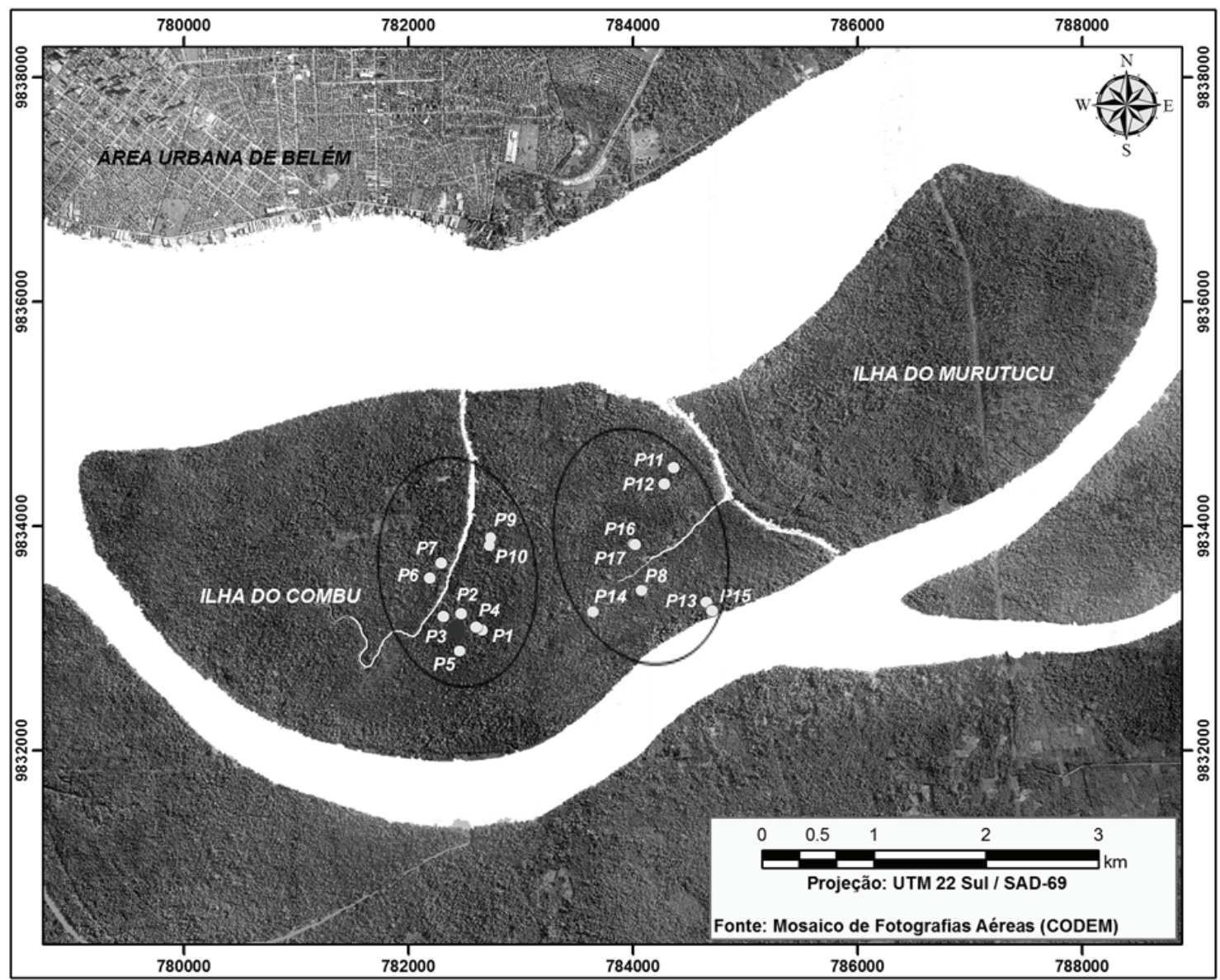

Figura1. Mapa de localização da Ilha do Combu, no município de Belém, Pará, Brasil, com indicação das parcelas (pontos brancos) nos dois ambientes estudados: floresta de Várzea alta (elipse à esquerda) e floresta de Várzea baixa (elipse à direita). Fonte: adaptado de Jardim \& Vieira (2001).

Figure1. Location of the Area of Combu Island, in the municipality of Belém, Pará State, Brazil, with indication of the plots (black dots) in two studied environments: High Várzea Forest (ellipse on the left) and Low Várzea Forest (ellipse on the right). Source: Jardim \& Vieira (2001). 
não apresentou especificidade quanto ao tipo de substrato, crescendo sobre dois ou mais tipos diferentes (tabela 1). Segundo Oliveira-e-Silva et al. (2002), isso ocorre devido às adaptações morfológicas das espécies, permitindo que colonizem diferentes ambientes e substratos.

A riqueza de espécies de briófitas encontrada em várzea na Ilha do Combu foi relativamente expressiva se comparada ao estudo realizado na ilha marinha Algodoal-Maiandeua, para a qual foram reportadas 14 espécies de briófitas por Ilkiu-Borges et al. (2009). A baixa riqueza pode estar relacionada à característica dos ambientes de coletas já apontados como ambientes adversos; e as espécies que os colonizam são aquelas que apresentam grande amplitude ecológica. Esse resultado foi evidente neste trabalho, onde maioria das espécies possui amplitude ecológica alta (Ilkiu-Borges et al. 2009).

Quando comparados à riqueza de musgos do presente trabalho, estudos realizados somente com musgos na Ilha do Marajó (Lisboa \& Maciel 1994, Lisboa et al. 1998, 1999) e na Ilha de Trambioca (Souza \& Lisboa 2005) apresentaram maior riqueza que na Ilha do Combu (83 espécies para o Marajó e 40 espécies para Trambioca). A diferença de riqueza entre as áreas está, possivelmente, relacionada aos diferentes esforços amostrais empregados e à diversidade de ambientes coletados em cada um desses estudos.

As espécies coletadas estão organizadas sob as suas respectivas divisões, na ordem alfabética de famílias, gênero e espécie. A espécie ilustrada foi escolhida pela ausência de ilustração em literatura. Para cada espécie apresentada são fornecidos comentários ecológicos e a distribuição geográfica no Brasil, e quando pertinenten, são apresentados comentários morfológicos e taxonômicos.

\section{MARCHANTIOPHYTA}

\section{LEJEUNEACEAE}

1. Archilejeunea auberiana (Mont.) A. Evans, Bull. Torrey Bot. Club 35: 168. 1908.

Material selecionado: BRASIL. PARÁ: Belém, Ilha do Combu, Várzea, 20-VIII-2008, O.S. Moura et al. 9 (MG); idem, ibidem, O.S. Moura et al. 33 (MG).

A espécie tem sido geralmente reportada para formações vegetais abertas, crescendo sobre troncos ou galhos na copa ou nas margens de florestas semidecíduas (Gradstein \& Costa 2003, Gradstein \&
Ilkiu-Borges 2009). Entretanto, também pode ocorrer sobre folhas no subosque de florestas de terra firme no Baixo Amazonas (Ilkiu-Borges \& Lisboa 2002). $\mathrm{Na}$ Ilha do Combu, foi coletada sobre cipó, galhos e tronco em decomposição.

Distribuição no Brasil: AC, AM, AP, BA, ES, MS, MT, PA, PE, PR, RJ, RO, RR, RS e SP.

2. Archilejeunea fucescens (Hampe ex Lehm.) Fulford, Bryologist 45: 174. 1942.

Material selecionado: BRASIL. PArÁ: Belém, Ilha do Combu, várzea, 26-IX-2008, O. S. Moura et al. 195 (MG).

É comum na Amazônia e no escudo das Guianas, crescendo tanto no subosque quanto na copa de florestas, tendo sido reportada em florestas de terra firme e várzea no Baixo Amazonas, adotando como substrato troncos e galhos de árvores vivas ou em decomposição (Gradstein 1994, Gradstein \& Ilkiu-Borges 2009). Na Ilha do Combu, ocorreu apenas sobre tronco vivo.

Distribuição no Brasil: AC, AM, BA, ES, PA, PE, RJ, RR e SP.

3. Archilejeunea parviflora (Nees) Schiffn., Hedwigia 33: 181. 1894.

Material selecionado: BRASIL. PARÁ: Belém, Ilha do Combu, Várzea, 20-VIII-2008, O.S. Moura et al. $177(\mathrm{MG})$.

Está presente em florestas de baixas altitudes, periodicamente inundadas ou não, até $1.500 \mathrm{~m}$, no subosque ou ao longo de igarapés ou rios, sobre a base de troncos, raízes, troncos em decomposição ou sobre pedras (Gradstein 1994, Gradstein \& Costa 2003, Gradstein \& Ilkiu-Borges 2009). Na Ilha do Combu, ocorreu sobre tronco vivo ou em decomposição e sobre raiz no chão.

Distribuição no Brasil: AC, AM, AP, BA, ES, MG, MS, MT, PA, PE, RJ, RO, RR, RS, SC e SP.

4. Ceratolejeunea coarina (Gottsche) Steph., Spec. Hep. 5: 402: 1913.

Material selecionado: BRASIL. PARÁ: Belém, Ilha do Combu, Várzea, 27-VII-2008, O.S. Moura et al. 71 (MG).

A maioria dos espécimes estudados na Ilha do Combu apresentou filídios com margem inteira, lóbulos frequentemente reduzidos e raramente com utrículos. 
Tabela 1. Espécies reportadas para a Ilha do Combu, Belém, PA, Brasil. Ecossistemas - FVA: Floresta de Várzea alta; FVB: Floresta de Várzea baixa. Espécie $\times$ Substrato - C: corticícola; E: epíxila; F: epifila; T: sobre termiteiro. ${ }^{*}$ Nova ocorrência para o Estado do Pará.

Table 1. Number of ocurrence of species reported for Combu Island, Belém, Pará State, Brazil. Ecosystems: High Várzea Forest (HVF) and Low Várzea Forest (LVF). Species $\times$ Substrate - C: corticicolous; E: epixylic; F: epiphyllous; T: on termite nest. * New record for the Pará State.

\begin{tabular}{|c|c|c|c|c|c|c|c|}
\hline Espécies & $\mathrm{N}^{\circ}$ de ocorrências & FVA & FVB & $\mathrm{C}$ & $\mathrm{E}$ & $\mathrm{F}$ & $\mathrm{T}$ \\
\hline \multicolumn{8}{|l|}{ BRYOPHYTA } \\
\hline Callicostella pallida (Hornsch.) Ångstr. & 24 & 19 & 5 & 14 & 10 & - & - \\
\hline Calymperes afzelii $\mathrm{Sw}$. & 11 & 8 & 3 & 9 & 2 & - & - \\
\hline Calymperes erosum Müll. Hal. & 2 & 0 & 2 & 1 & 1 & - & - \\
\hline Calymperes loncophyllum Schwägr. & 2 & 2 & - & 2 & & - & - \\
\hline Calymperes palisotii Schwägr. & 57 & 31 & 26 & 43 & 13 & 1 & - \\
\hline *Crossomitrium epiphyllum (Mitt.) Müll. Hal. & 1 & 1 & - & 1 & - & - & - \\
\hline Crossomitrium patrisae (Brid.) Müll. Hal. & 7 & 7 & - & 4 & 1 & 2 & - \\
\hline Fissidens guianensis Mont. & 21 & 16 & 5 & 17 & 4 & - & - \\
\hline Fissidens hornschuchii Mont. & 14 & 10 & 4 & 13 & 1 & - & - \\
\hline Fissidens pellucidus Hornsch. & 2 & 2 & - & 1 & 1 & - & - \\
\hline Henicodium geniculatum (Mitt.) W.R. Buck & 1 & - & 1 & - & 1 & - & - \\
\hline Isopterygium subbrevisetum (Hampe) Broth. & 2 & 2 & - & 1 & 1 & - & - \\
\hline Isopterygium tenerum (Sw.) Mitt. & 16 & 15 & 1 & 11 & 4 & - & - \\
\hline *Lepidopilum affine Müll. Hal. & 4 & 3 & 1 & 4 & - & - & - \\
\hline Lepidopilum surinamense Müll. Hal. & 1 & 1 & - & - & 1 & - & - \\
\hline Neckeropsis disticha (Hedwig) Kindberg & 19 & 16 & 3 & 11 & 8 & - & - \\
\hline Neckeropsis undulata (Hedwig) Reichardt & 8 & 8 & - & 8 & - & - & - \\
\hline Octoblepharum albidum Hedwig & 1 & - & 1 & - & 1 & - & - \\
\hline Pelekium involvens (Hedwig) Touw & 2 & 2 & - & 1 & 1 & - & - \\
\hline Pelekium scabrosulum (Mitt.) Touw & 5 & 4 & 1 & 2 & 3 & - & - \\
\hline Pilotrichum evanescens (Müll. Hal.) Crosby & 8 & 5 & 3 & 4 & 4 & - & - \\
\hline Sematophyllum subpinnatum (Brid.) E. Britton & 1 & 1 & - & - & 1 & - & - \\
\hline Taxithelium concavum (Hook.) Spruce ex J. Florsch. & 1 & 1 & - & - & 1 & - & - \\
\hline Taxithelium planum (Brid.) Mitt. & 9 & 6 & 3 & 4 & 5 & - & - \\
\hline Trichosteleum papillosum (Hornsch.) A. Jaeger & 7 & 2 & 5 & 2 & 5 & - & - \\
\hline Trichosteleum subdemissum (Besch.) A. Jaeger & 4 & 2 & 2 & 2 & 2 & - & - \\
\hline Vesicularia vesicularis (Schwägr.) Broth. & 1 & 1 & - & 1 & - & - & - \\
\hline \multicolumn{8}{|l|}{ MARCHANTIOPHYTA } \\
\hline Arquilejeunea auberiana (Mont.) A. Evans & 22 & 16 & 6 & 12 & 8 & 3 & - \\
\hline Arquilejeunea fucescens (Hampe ex Lehm.) Fulford & 1 & - & 1 & 1 & - & - & - \\
\hline Arquilejeunea parviflora (Nees) Schiffn. & 8 & 3 & 5 & 8 & - & - & - \\
\hline Ceratolejeunea coarina (Gottsche) Steph. & 55 & 27 & 28 & 40 & 11 & 5 & - \\
\hline Ceratolejeunea cornuta (Lindenb.) Schiffn. & 81 & 50 & 31 & 63 & 14 & 4 & - \\
\hline Ceratolejeunea cubensis (Mont.) Schiffn. & 10 & 7 & 3 & 8 & 2 & - & - \\
\hline Ceratolejeunea guianensis (Nees \& Mont.) Steph. & 2 & 2 & - & 2 & - & - & - \\
\hline Cheilolejeunea adnata (Kunze) Grolle & 2 & - & 2 & 2 & - & - & - \\
\hline Cheilolejeunea aneogyna (Spruce) A. Evans & 1 & 1 & - & - & 1 & - & - \\
\hline
\end{tabular}


Tabela 1 (continuação)

\begin{tabular}{|c|c|c|c|c|c|c|c|}
\hline Espécies & $\mathrm{N}^{\mathrm{o}}$ de ocorrências & FVA & FVB & C & E & $F$ & $\mathrm{~T}$ \\
\hline $\begin{array}{l}\text { Cheilolejeunea discoidea (Lehm. \& Lindenb.) Kachr. } \\
\text { \& R.M. Schust. }\end{array}$ & 3 & 1 & 2 & 3 & 0 & - & - \\
\hline $\begin{array}{l}\text { Cheilolejeunea oncophylla (Ångstr.) Grolle \& M.E. } \\
\text { Reiner }\end{array}$ & 8 & 2 & 6 & 7 & 1 & - & - \\
\hline Cheilolejeunea rigidula (Mont.) R.M. Schust. & 4 & 2 & 2 & 2 & 2 & - & - \\
\hline Cololejeunea camillii (Lehm.) A. Evans & 34 & 16 & 18 & 19 & 1 & 14 & - \\
\hline Cololejeunea cardiocarpa (Mont.) A. Evans & 12 & 6 & 6 & - & - & 12 & - \\
\hline Cololejeunea contractiloba A. Evans & 3 & 2 & 1 & 3 & - & - & - \\
\hline $\begin{array}{l}\text { *Cololejeunea microscopica var. exigua (A. Evans) } \\
\text { Lücking \& Pócs }\end{array}$ & 1 & 1 & - & 1 & - & - & - \\
\hline Cololejeunea obliqua (Nees \& Mont.) S.W. Arnell & 4 & 4 & - & 3 & - & 1 & - \\
\hline Cololejeunea subcardiocarpa Tixier & 5 & 1 & 4 & 1 & - & 4 & - \\
\hline Cololejeunea winkleri Morales \& A. Lücking & 2 & 2 & - & 2 & - & - & - \\
\hline Cyclolejeunea luteola (Spruce) Grolle & 1 & 1 & - & - & 1 & - & - \\
\hline $\begin{array}{l}\text { Frullanoides corticalis (Lehm. \& Lindenb.) van } \\
\text { Slageren }\end{array}$ & 1 & 1 & - & - & 1 & - & - \\
\hline Harpalejeunea stricta (Lindenb. \& Gottsche) Steph. & 1 & 1 & - & 1 & - & - & - \\
\hline Lejeunea adpressa Nees & 52 & 35 & 17 & 41 & 9 & 2 & - \\
\hline Lejeunea caulicalyx (Steph.) M.E. Reiner \& Goda & 1 & 1 & - & 1 & - & - & - \\
\hline $\begin{array}{l}\text { Lejeunea combuensis O.S. Moura, Ilk.-Borg. \& M.E. } \\
\text { Reiner }\end{array}$ & 4 & - & 4 & 3 & 1 & - & - \\
\hline Lejeunea controversa Gottsche & 10 & 6 & 4 & 10 & - & - & - \\
\hline Lejeunea huctumalsensis Lindenb. \& Gottsche & 1 & 1 & - & 1 & - & - & - \\
\hline Lejeunea laetevirens Nees \& Mont. & 33 & 19 & 14 & 31 & 2 & - & - \\
\hline Lejeunea obidensis Spruce & 13 & 8 & 5 & 12 & 1 & - & - \\
\hline Lejeunea phyllobola Nees \& Mont. & 23 & 21 & 2 & 20 & 2 & 1 & - \\
\hline Lejeunea quinqueumbonata Spruce & 5 & 3 & 2 & 1 & 4 & - & - \\
\hline Lejeunea tapajosensis Spruce & 6 & 6 & - & 5 & 1 & - & - \\
\hline Leptolejeunea elliptica (Lehm. \& Lindenb.) Schiffn. & 2 & 2 & - & - & - & 2 & - \\
\hline Lopholejeunea subfusca (Nees) Schiffn. & 23 & 17 & 6 & 13 & 10 & - & - \\
\hline Microlejeunea acutifolia Steph. & 13 & 11 & 2 & 12 & 1 & - & - \\
\hline Microlejeunea epiphylla Bischl. & 12 & 11 & 1 & 7 & 4 & 1 & - \\
\hline Rectolejeunea berteroana (Gottsche ex Steph.) A. Evans & 62 & 37 & 25 & 50 & 5 & 6 & - \\
\hline Rectolejeunea emarginuliflora (Gottsche) A. Evans & 8 & 5 & 3 & 6 & 1 & 1 & - \\
\hline Stictolejeunea balfourii (Mitt.) E.W. Jones & 53 & 34 & 19 & 40 & 12 & 1 & - \\
\hline Stictolejeunea squamata (Willd. ex Weber) Schiffn. & 94 & 52 & 42 & 84 & 8 & 1 & 1 \\
\hline $\begin{array}{l}\text { Symbiezidium barbiflorum (Lindenb. \& Gottsche) A. } \\
\text { Evans }\end{array}$ & 74 & 33 & 41 & 64 & 9 & 1 & - \\
\hline $\begin{array}{l}\text { Plagiochila gymnocalycina (Lehm. \& Lindenb.) } \\
\text { Lindenb. }\end{array}$ & 14 & 11 & 3 & 11 & 3 & - & - \\
\hline Plagiochila montagnei Nees & 34 & 19 & 15 & 31 & 3 & - & - \\
\hline Radula javanica Gottsche & 53 & 42 & 11 & 47 & 5 & 1 & - \\
\hline Radula mammosa Spruce & 6 & 5 & 1 & 3 & - & 3 & - \\
\hline TOTAL & 1.088 & 690 & 398 & 827 & 194 & 66 & 1 \\
\hline
\end{tabular}


É comum em florestas de baixas altitudes a submontanhosas, sobre troncos vivos ou em decomposição, folhas vivas ou rochas (Dauphin 2003, Gradstein \& Costa 2003, Gradstein \& Ilkiu-Borges 2009). Na Ilha do Combu, foi coletada sobre cipós, folhas vivas e tronco vivo ou em decomposição.

Distribuição no Brasil: AC, AL, AM, AP, BA, CE, ES, GO, MA, MG, PA, PB, PE, PR, RJ, RO, RR, SC, SE e SP.

5. Ceratolejeunea cornuta (Lindenb.) Steph. in Engler, Pflanzenwelt Ost-Afrikas C: 65. 1895.

Material selecionado: BRASIL. PARÁ: Belém, Ilha do Combu, Várzea, 26-IX-2008, O.S. Moura et al. 185 (MG).

É uma espécie bastante comum, que ocorre em florestas de baixas altitudes até submontanhosas e em formações vegetais abertas, sobre troncos, rochas e folhas vivas (Ilkiu-Borges \& Lisboa 2002, Gradstein \& Ilkiu-Borges 2009). Na Ilha do Combu, ocorreu sobre cipós e troncos vivos ou em decomposição.

Distribuição no Brasil: AC, AM, AP, BA, CE, MG, PA, PE, PR, RJ, RO, RR, SC, SE e SP.

6. Ceratolejeunea cubensis (Mont.) Schiffn. in Engler \& Prantl, Natürl. Pflanzenfam. 1(3): 125. 1893.

Material selecionado: BRASIL. PARÁ: Belém, Ilha do Combu, Várzea, 20-VIII-2008, O.S. Moura et al. 1 (MG).

Foi reportada em florestas de baixas altitudes até montanhosas, sobre troncos vivos ou em decomposição e sobre folhas (Zartman \& Ilkiu-Borges 2007, Gradstein \& Ilkiu-Borges 2009). Na Ilha do Combu, ocorreu tanto sobre tronco vivo quanto em decomposição.

Distribuição no Brasil: AC, AL, AM, AP, BA, CE, ES, PA, PB, PE, RJ, RO, SC e SP.

7. Ceratolejeunea guianensis (Nees \& Mont.) Steph., Spec. Hepat. 5: 416. 1913.

Material selecionado: BRASIL. PARÁ: Belém, Ilha do Combu, Várzea, 27-VIII-2008, O.S. Moura et al. 135 (MG).

A espécie ocorre em florestas tropicais de baixas altitudes no subosque ou na copa, sobre tronco vivo ou em decomposição, cipós e às vezes sobre folhas vivas (Ilkiu-Borges \& Lisboa 2002, Gradstein \& Ilkiu-Borges 2009). No Combu, ocorreu apenas sobre tronco vivo.

Distribuição no Brasil: AM, PA e PE.
8. Cheilolejeunea adnata (Kunze) Grolle, J. Bryol. 9: 529. 1977.

Material selecionado: BRASIL. PARÁ: Belém, Ilha do Combu, Várzea, 26-IX-2008, O.S. Moura et al. 214 (MG).

Pode ocorrer sobre troncos em florestas de baixas altitudes a submontanhosas ou em formações vegetais abertas, sobre troncos e galhos vivos ou em decomposição e ocasionalmente sobre folhas vivas (Gradstein \& Costa 2003, Gradstein \& Ilkiu-Borges 2009). Na Ilha do Combu, ocorreu sobre tronco de árvore viva.

Distribuição no Brasil: AC, AL, AM, AP, BA, ES, MT, PA, PE, PR, RN, RR, SC e SP.

9. Cheilolejeunea aneogyna (Spruce) A. Evans, Trans. Connecticut Acad. Arts Sci. 10: 440. 1900.

Material selecionado: BRASIL. PARÁ: Belém, Ilha do Combu, Várzea, 27-VIII-2008, O.S. Moura et al. 131 (MG).

Anteriormente, essa espécie estava subordinada ao gênero Trachylejeunea, o qual foi sinonimizado com Cheilolejeunea por Gradstein \& Ilkiu-Borges (2009).

Cheilolejeunea aneogyna foi reportada no subosque de florestas de baixas altitudes a submontanhosas, sobre troncos vivos ou em decomposição ou sobre espinhos de palmeiras (Gradstein \& Costa 2003). Na Ilha do Combu, ocorreu sobre tronco em decomposição.

Distribuição no Brasil: AM, BA, ES, PA, PE, RO e SP.

10. Cheilolejeunea discoidea (Lehm. \& Lindenb.) Kachroo \& R.M. Schust., J. Linn. Soc. London Bot. 56: 509. 1961.

Material selecionado: BRASIL. PARÁ: Belém, Ilha do Combu, Várzea, 20-VIII-2008, O.S. Moura et al. 8 (MG).

Pode ser encontrada em florestas tropicais de baixas altitudes até $2.400 \mathrm{~m}$, assim como em formações vegetais abertas (Gradstein \& Costa 2003, Ilkiu-Borges et al. 2009). É geralmente coletada sobre troncos vivos e em decomposição (Visnadi \& Vital 2001, Bastos \& Yano 2006). Na Ilha do Combu, ocorreu como epífila sobre troncos e cipó.

Distribuição no Brasil: BA, DF, ES, GO, MG, MS, MT, PA, SE e SP. Foi referida pela primeira vez para 
o Estado do Pará por Ilkiu-Borges et al. (2009) na Ilha de Algodoal-Maiandeua, sendo este o segundo registro para o Estado.

11. Cheilolejeunea oncophylla (Ångstr.) Grolle \& E.

Reiner, J. Bryol. 19: 781. 1997.

Material selecionado: BRASIL. PARÁ: Belém, Ilha do Combu, Várzea, 26-IX-2008, O.S. Moura et al. 207 (MG).

Os anfigastros na espécie variam de 1,5-3 $\times$ a largura do caulídio (Grolle \& Reiner-Drehwald 1997, Gradstein \& Costa 2003), entretanto, no espécime O.S. Moura et al. 207, os mesmos variavam de 3-4,5 × a largura do caulídio.

Ocorre em florestas de baixas altitudes a montanhosas, até $3.210 \mathrm{~m}$, geralmente sobre troncos vivos, às vezes sobre rochas (Grolle \& ReinerDrehwald 1997, Gradstein \& Costa 2003). Na Ilha do Combu, foi encontrada geralmente sobre tronco de árvores vivas e apenas uma amostra sobre tronco em decomposição.

Distribuição no Brasil: AP, BA, MG, PA, PR, RJ, RR, SC e SP.

12. Cheilolejeunea rigidula (Mont.) R.M. Schust., Castanea 36: 102. 1971.
Material selecionado: BRASIL. PArÁ: Belém, Ilha do Combu, Várzea, 16-IX-2008, O.S. Moura et al. 143 (MG).

É uma espécie extremamente comum que ocorre tanto no subosque quanto na copa de florestas de baixas altitudes a submontanhosas, assim como em mangue, plantações, árvores isoladas e vários tipos de formações abertas (Gradstein \& Costa 2003, Gradstein \& Ilkiu-Borges 2009). No Baixo Amazonas, foi registrada em florestas de várzea, terra firme e secundária (Ilkiu-Borges \& Lisboa 2002). É geralmente coletada sobre troncos de árvores vivas e raramente sobre rochas, troncos em decomposição e folhas (Ilkiu-Borges \& Lisboa 2002, Gradstein \& Costa 2003). Na Ilha do Combu, ocorreu em tronco vivo e em decomposição.

Distribuição no Brasil: AC, AL, AM, AP, BA, CE, DF, ES, GO, MA, MG, MS, MT, PA, PB, PE, PR, RJ, RR, SC, SE, SP e TO.

13. Cololejeunea camillii (Lehm.) A. Evans, Bryologist 15: 59. 1912.

Material selecionado: BRASIL. PARÁ: Belém, Ilha do Combu, Várzea, 20-VIII-2008, O.S. Moura et al. 8 (MG).

\section{$\square \mathrm{N}^{\circ}$ de ocorrência $\square$ Riqueza}

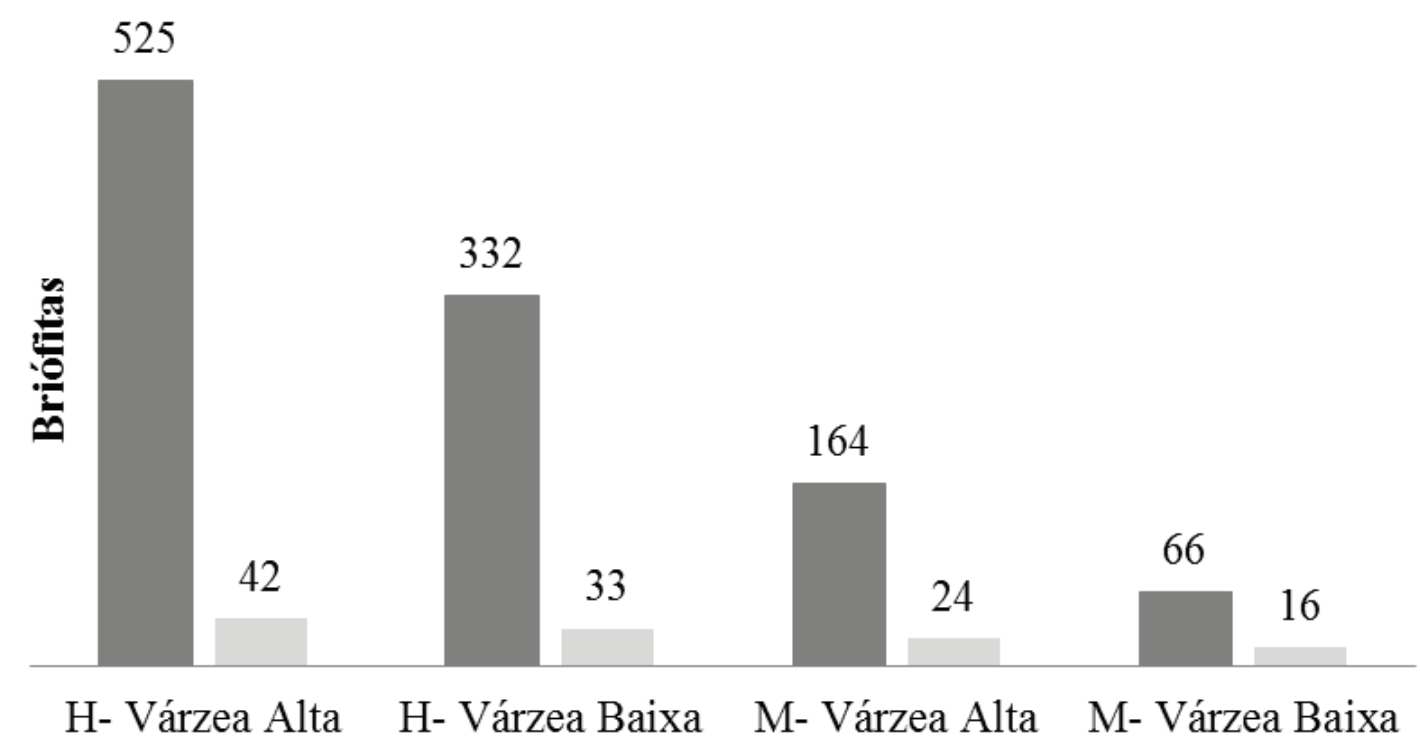

Figura 2. Comparação no número de ocorrência e riqueza de musgos e hepáticas em Floresta de Várzea Alta e Floresta de Várzea Baixa na Ilha do Combu, Belém, Pará, Brasil.

Figure 2. Comparison of the number of records and richness of mosses and hepatics in High Várzea Forest and Low Várzea Forest in Combu Island, Belém, Pará State, Brazil. 
Na Ilha do Combu, a espécie apresentou somente filídios elobulados.

Essa espécie foi reportada em florestas de baixas altitudes até $1.600 \mathrm{~m}$, onde ocorre geralmente sobre folhas vivas e, ocasionalmente, sobre troncos vivos ou em decomposição (Gradstein \& Costa 2003). Na área de estudo, foi coletada sobre cipó, folhas e tronco vivo em locais sombreados.

Distribuição no Brasil: AL, AM, CE, MG, PA, RJ e SP.

14. Cololejeunea cardiocarpa (Mont.) A. Evans, Mem. Torrey Bot. Club. 8: 172. 1902.

Material selecionado: BRASIL. PARÁ: Belém, Ilha do Combu, Várzea, 27-IX-2008, O.S. Moura et al. 285 (MG).

Essa espécie ocorre em florestas de baixas altitudes a submontanhosas, crescendo tipicamente sobre folhas, mas também sobre galhos finos e rochas (Gradstein \& Costa 2003, Gradstein \& Ilkiu-Borges 2009). Na Ilha do Combu, foi coletada exclusivamente sobre folhas.

Distribuição no Brasil: AM, AP, BA, ES, GO, MG, MS, MT, PA, PB, PE, PR, RJ, RO, RR, SC, SE e SP.

15. Cololejeunea contractiloba A. Evans, American Journal of Botany 5: 131. 1918.

Material selecionado: BRASIL. PArÁ: Belém, Ilha do Combu, Várzea, 20-VIII-2008, O.S. Moura et al. 20 (MG).

No Brasil, foi registrada em florestas de várzea no Baixo Amazonas e em floresta estacional até $900 \mathrm{~m}$ de altitude, podendo ocorrer sobre tronco vivo ou em decomposição (Ilkiu-Borges \& Lisboa 2002, 2004, Bastos 2004). Na Ilha do Combu, ocorreu apenas sobre tronco vivo.

Distribuição no Brasil: BA (Bastos 2004) e PA. Ainda foi referida por Bastos (2004) e Yano (2006) para o Rio de Janeiro e São Paulo. O primeiro autor não identificou a fonte de sua consulta para esses dados e Yano (2006) fez referência ao trabalho de Gradstein \& Costa (2003), os quais reportaram a espécie para o Estado do Pará, indicando o trabalho de Ilkiu-Borges \& Lisboa (2004) na Estação Científica Ferreira Penna, em Caxiuanã. De acordo com a Lista de Espécies da Flora do Brasil (Bastos 2012), C. contractiloba ocorre apenas no Estado do Pará.

16. Cololejeunea microscopica (Taylor) A. Evans var. exigua (A. Evans) Lücking \& Pócs, Haussknechtia Beih. 7: 27. 1997.
Material selecionado: BRASIL. PARÁ: Belém, Ilha do Combu, Várzea, 27-VIII-2008, O.S. Moura et al. 74 (MG).

Ocorre geralmente no subosque de florestas de baixas altitudes a submontanhosas, sobre folhas e troncos vivos (Gradstein \& Costa 2003, Gradstein \& Ilkiu-Borges 2009). Na Ilha do Combu, ocorreu apenas sobre tronco vivo.

Distribuição no Brasil: RR e SP. Primeira referência para o Estado do Pará.

17. Cololejeunea obliqua (Nees \& Mont.) S.W. Arnell in Schiffner \& Arnell, Denkschr. Österr. Akad. Wiss., Math.-Naturwiss. K1. 111: 97. 1964.

Material selecionado: BRASIL. PARÁ: Belém, Ilha do Combu, Várzea, 20-VIII-2008, O.S. Moura et al. 82 (MG).

Ocorre em florestas de baixas altitudes, como epífita ou epífila (Tixier 1985, Gradstein \& Costa 2003, Gradstein \& Ilkiu-Borges 2009). Na Ilha do Combu, ocorreu sobre tronco vivo e folhas.

Distribuição no Brasil: AC, AM, AP, BA, PA, PE, PR, RJ, SC e SP.

18. Cololejeunea subcardiocarpa Tixier, Bradea 3: 39. f. 3. 1980.

Material selecionado: BRASIL. PARÁ: Belém, Ilha do Combu, Várzea, 20-VIII-2008, O.S. Moura et al. 33 (MG).

Reportada, no Brasil, em florestas de baixas altitudes até montanhosas, exclusivamente sobre folhas vivas (Gradstein \& Costa 2003). Na Ilha do Combu, também ocorreu sobre folha.

Distribuição no Brasil: AC, AL, AM, BA, CE, ES, GO, MG, MT, PA, PE, PR, RJ, SC e SP.

19. Cololejeunea winkleri Morales \& A. Lücking, Nova Hedwigia 60: 120. 1995.

Material selecionado: BRASIL. PARÁ: Belém, Ilha do Combu, Várzea, 20-VIII-2008, O.S. Moura et al. 25 (MG).

Foi reportada ocorrendo em florestas de baixas altitudes no subosque, sobre folhas vivas (Ilkiu-Borges \& Lisboa 2002, Gradstein \& Costa 2003, Zartman \& Ilkiu-Borges 2007, Gradstein \& Ilkiu-Borges 2009, 2004). Na Ilha do Combu, ocorreu sobre tronco vivo. Distribuição no Brasil: AM e PA. 
20. Cyclolejeunea luteola (Spruce) Grolle, Wiss. Ztschr. Friedrich-Schiller-univ. Jena, naturwiss. Reihe 33(6): 761. 1984.

Material selecionado: BRASIL. PARÁ: Belém, Ilha do Combu, Várzea, 20-VIII-2008, O.S. Moura et al. 30 (MG).

Ocorre em florestas de baixas altitudes até montanhosas sobre troncos vivos ou em decomposição e sobre rochas (Gradstein \& Costa 2003, Gradstein \& Ilkiu-Borges 2009). Na Ilha do Combu, ocorreu sobre tronco em decomposição.

Distribuição no Brasil: AM, BA, CE, MG, MT, PA, PE, RJ, RR e SP.

21. Frullanoides corticalis (Lehm. \& Lindenb.) van Slageren, Meded. Bot. Mus. Herb. Rijksuniv. Utrecht 544: 84. 1985.

Material selecionado: BRASIL. PARÁ: Belém, Ilha do Combu, Várzea, 20-VIII-2008, O.S. Moura et al. 22 (MG).

Ocorre em formações vegetais abertas no litoral ou em zonas urbanas, além de mangues, bosques, florestas secundárias e plantações; é uma espécie xerotolerante, que comumente ocorre como epífita ou rupícola (Gradstein 1994, van Slageren 1985). Na Ilha do Combu, foi encontrada sobre tronco vivo.

Distribuição no Brasil: BA, MG, MT, RJ, RR e SP. Para o Estado do Pará, esta espécie foi coletada pela primeira vez no município de Soure por L.P.C. Macedo (dados não publicados), sendo este o segundo registro de ocorrência no Estado.

22. Harpalejeunea stricta (Lindenb. \& Gottsche) Steph., Hedwigia 27: 291. 1888.

Material selecionado: BRASIL. PARÁ: Belém, Ilha do Combu, Várzea, 27-VIII-2008, O.S. Moura et al. 135 (MG).

Ocorre em vegetação aberta ou na copa de árvores de florestas de baixas altitudes, suportando exposição ao sol, geralmente sobre troncos vivos (Schuster 1980, Gradstein \& Costa 2003, Gradstein \& Ilkiu-Borges 2009). Na Ilha do Combu, ocorreu sobre tronco vivo.

Distribuição no Brasil: AL, BA, PA, PE, MG, RJ, SC e SP.

23. Lejeunea adpressa Nees in Gottsche, Lindenberg \& Nees, Syn. Hep.: 380. 1845.

Material selecionado: BRASIL. PARÁ: Belém, Ilha do Combu, Várzea, 16-IX-2008, O.S. Moura et al. 228 (MG).
Ocorre desde o nível do mar até $1.900 \mathrm{~m}$ de altitude em diferentes tipos de florestas, incluindo florestas perturbadas ou vegetação secundária, sobre troncos ou galhos de árvores, lianas e sobre folhas vivas (Reiner-Drehwald 2009). Na Ilha do Combu, foi encontrada sobre cipó, tronco vivo ou em decomposição e sobre folhas.

Distribuição no Brasil: AM, ES, PR e SP (ReinerDrehwald 2009). Essa espécie ainda foi citada para BA, PA, RJ e SP, por Bastos \& Yano (2009), como L. magnoliae Lindenb. \& Gottsche (= L. adpressa, fide Reiner-Drehwald 2009). No Brasil, a espécie vinha sendo tratada como L. caespitosa Lindenb. sensu Schuster (1980), o qual considerou Lejeunea longifissa Steph. (= L. adpressa, fide Reiner-Drehwald 2009) como sinônimo de L. caespitosa (ver discussão em Reiner-Drehwald 2009).

24. Lejeunea caulicalyx (Steph.) E. Reiner \& Goda, J. Hattori Bot. Lab. 89: 13. 2000.

Material selecionado: BRASIL. PARÁ: Belém, Ilha do Combu, Várzea, 27-VIII-2008, O.S. Moura et al. 134 (MG).

Ocorre em florestas de baixas altitudes, perturbadas ou não, restingas e mangues, sendo comumente encontrada colonizando troncos vivos ou em decomposição (Reiner-Drehwald \& Goda 2000). $\mathrm{Na}$ Ilha do Combu, ocorreu sobre tronco vivo.

Distribuição no Brasil: AC, BA, CE, ES, MS, MT, PA, PE, PR, RJ, RR e SP. Essa espécie foi referida pela primeira vez para o Estado do Pará por Tavares (2009), sendo esta a segunda referência para o Estado.

25. Lejeunea combuensis O.S. Moura, Ilk.-Borg. \& M.E. Reiner, Nova Hedw. 95(1-2): 197. 2012.

Material selecionado: BRASIL. PARÁ: Belém, Ilha do Combu, Várzea, 26-IX-2008, O.S. Moura et al. 207(MG).

Distribuição no Brasil: PA (Ilha do Combu).

A espécie tem como característica mais marcante os filídios ovalados com margens crenuladas a crenadas e ápice geralmente variando de obtuso a agudo, em combinação com o perianto cilíndrico, liso (sem quilhas), com ápice recessado e sem rostro. No Combu, ocorreu sobre tronco vivo e em decomposição.

26. Lejeunea controversa Gottsche in Gottsche \& Rabenh., Hepat. Eur.: 556. 1873.

Material selecionado: BRASIL. PARÁ: Belém, Ilha do Combu, Várzea, 27-IX-2008, O.S. Moura et al. 244 (MG). 
Ocorre em florestas de baixas altitudes a submontanhosas, sobre troncos de árvores ou arbustos, sobre folhas vivas e rochas próximas a cursos d'água (Gradstein \& Ilkiu-Borges 2009). Na Ilha do Combu, ocorreu exclusivamente sobre tronco vivo.

Distribuição no Brasil: AC, AM, BA, MS, PA, RJ e SP.

27. Lejeunea huctumalcensis Lindenb. \& Gottsche in Gottsche, Lindenberg \& Nees, Syn. Hep.: 762. 1847.

Material selecionado: BRASIL. PARÁ: Belém, Ilha do Combu, Várzea, 27-VIII-2008, O.S. Moura et al. 103 (MG).

Ocorre em florestas não perturbadas de baixas altitudes a montanhosas, sobre troncos vivos ou em decomposição e, mais raramente, sobre folhas (Reiner-Drehwald \& Ilkiu-Borges 2007). Na Ilha do Combu, ocorreu sobre tronco vivo.

Distribuição no Brasil: AM, BA, PA e SP.

28. Lejeunea laetevirens Nees \& Mont. in Ramón de la Sagra, Hist. Phys. Bot. Plant. Cell. Cuba 9: 469. 1842.

Material selecionado: BRASIL. PARÁ: Belém, Ilha do Combu, Várzea 16-IX-2008, O.S. Moura et al. 150 (MG).

É uma espécie xerotolerante, geralmente encontrada em formações florestais de baixas altitudes a montanhosas, plantações ou em formações vegetais abertas, como cerrado, restinga ou em árvores isoladas, sobre troncos vivos e rochas, raramente sobre folhas (Gradstein \& Costa 2003, Gradstein \& Ilkiu-Borges 2009). Na Ilha do Combu, ocorreu sobre cipó e tronco vivo.

Distribuição no Brasil: AC, AL, AM, AP, BA, CE, DF, ES, FN, GO, MA, MG, MS, MT, PA, PB, PE, RJ, RN, RR, RS, SC, SE e SP.

29. Lejeunea obidensis Spruce, Trans. \& Proc. Bot. Soc. Edinburgh 15: 227.1884.

Material selecionado: BRASIL. PARÁ: município de Belém, Ilha do Combu, Floresta de Várzea, 27-VIII-2008, O.S. Moura et al. 91 (MG).

É reconhecida através dos filídios distantes, raramente subimbricados, às vezes desiguais (menores em um lado do caulídio) (figura 3). Quanto à forma, os filídios são ovalados, com a base estreita, margens inteiras a crenuladas e ápice amplamente arredondado a obtuso. Os lóbulos são ovalados e inflados, mas estão geralmente reduzidos a 2-3 células. Os anfigastros são bem distantes, $1,5 \times$ a largura do caulídio, $50-60 \%$ bífidos, com lobos triangulares e eretos a \pm divergentes, com ápice apiculado a obtuso (figura 3). A espécie é autóica e os ginoécios geralmente apresentam uma inovação lejeuneóide estéril.

Até o presente, o único registro da espécie havia sido feito por Spruce (1884), quando de sua descrição, sem indicação do ambiente e substrato de ocorrência. $\mathrm{Na}$ Ilha do Combu, ocorreu sobre raiz e tronco vivos, em ambos os tipos de várzea (alta e baixa).

Distribuição no Brasil: PA. Spruce (1884) reportou a espécie para o Rio Amazonas perto de Óbidos, que provavelmente ainda corresponde ao território do Estado do Pará. Este é o segundo registro da espécie.

30. Lejeunea phyllobola Nees \& Mont. in Ramón de la Sagra, Hist. Phys. Cuba, Bot., Pl. Cell. 9: 471. 1842.

Material selecionado: BRASIL. PARÁ: Belém, Ilha do Combu, Várzea, 20-VIII-2008, O.S. Moura et al. 12 (MG).

Ocorre em formações florestais ou abertas em baixas altitudes, sobre troncos vivos e ocasionalmente sobre troncos em decomposição ou rochas (Gradstein $\&$ Costa 2003). Na Ilha do Combu, ocorreu sobre cipó e tronco vivo.

Distribuição: AC, AL, AM, BA, CE, DF, ES, GO, MA, MG, MS, MT, PA, RJ, RN, RS, SC e SP.

31. Lejeunea quinqueumbonata Spruce, Trans. \& Proc. Bot. Soc. Edinburgh 15: 230. 1884.

Material selecionado: BRASIL. PARÁ: Belém, Ilha do Combu, Várzea, 26-IX-2008, O.S. Moura et al. 222 (MG).

Ocorre em florestas de baixas altitudes, preferencialmente sobre tronco em decomposição, mas também sobre troncos vivos e rochas (ReinerDrehwald 2000). Na Ilha do Combu, ocorreu sobre tronco em decomposição.

Distribuição no Brasil: AM, BA, DF, ES, MS, MT, PA, PE, SC e SP.

32. Lejeunea tapajosensis Spruce, Trans. \& Proc. Soc. Bot. Edinburgh 15: 223. 1884.

Material selecionado: BRASIL. PARÁ: Belém, Ilha do Combu, Várzea, 16-IX-2008, O.S. Moura et al. 172 (MG). 


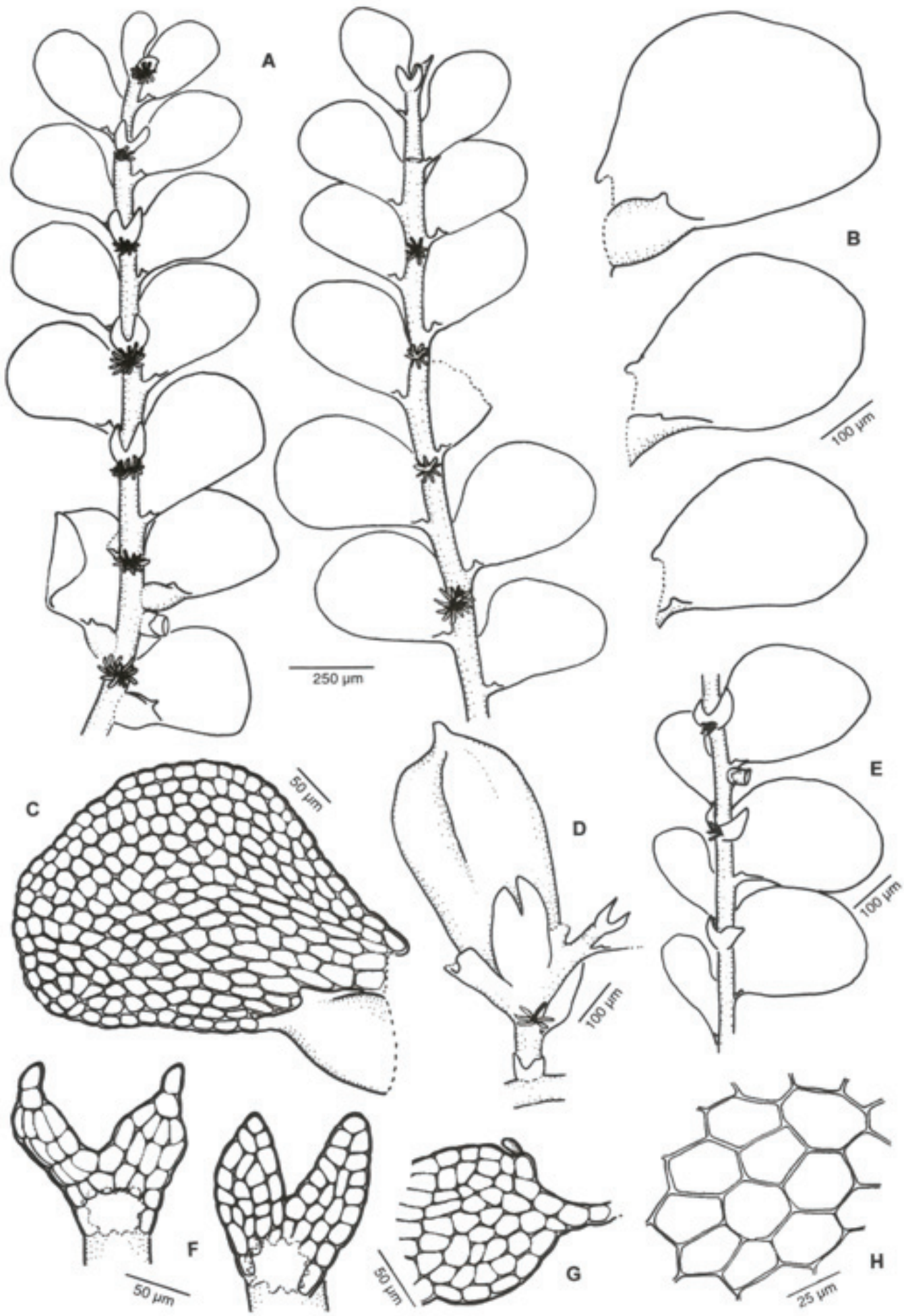

Figura 3. Lejeunea obidensis Spruce. A. Planta em vista ventral. B. Filídios, vista ventral. C. Filídio com células detalhadas, vista ventral. D. Ginoécio com perianto e inovação. E. Planta em vista ventral. F. Anfigástros. G. Lóbulo destacado do caulídio. H. Células medianas do filídio (A-D, F-H: O.S. Moura et al. 278; E: O.S. Moura et al. 91).

Figure 3. Lejeunea obidensis Spruce. A. Plant in ventral view. B. Leaves, ventral view. C. Leaf with detailed cells, ventral view. D. Gynoecia with perianth and innovation. E. Plant in ventral view. F. Underleaves. G. Lobule detached from caulidium. H. Cells of the leaf middle (A-D, F-H: O.S. Moura et al. 278; E: O.S. Moura et al. 91). 
Ocorre em florestas de baixas altitudes sobre tronco vivo (Gradstein \& Costa 2003, Gradstein \& Ilkiu-Borges 2009). Na Ilha do Combu, ocorreu sobre cipó em decomposição.

Distribuição no Brasil: AC, AM, BA, ES, PA, PE e RJ.

33. Leptolejeunea elliptica (Lehm. \& Lindenb.) Schiffn. in Engler \& Plantl, Nat. Pflanzenfam. 1(3): 126. 1893.

Material selecionado: BRASIL. PARÁ: Belém, Ilha do Combu, Várzea, 27-VIII-2008, O.S. Moura et al. 92 (MG).

Ocorre em florestas de baixas altitudes até montanhosas, sendo preferencialmente epífila, mas pode ocorrer sobre troncos vivos (Bischler 1969, Gradstein \& Costa 2003). Na Ilha do Combu, ocorreu sobre folha.

Distribuição no Brasil: AC, AL, AM, AP, BA, CE, DF, ES, GO, MG, MT, PA, PE, PR, RJ, RR, SC, SE e SP.

34. Lopholejeunea subfusca (Nees) Schiffn., Bot. Jahrb. Syst. 23: 593. 1897.

Material selecionado: BRASIL. PARÁ: Belém, Ilha do Combu, Várzea, 26-IX-2008, O.S. Moura et al. $210(\mathrm{MG})$.

Ocorre na copa ou na margem de florestas preservadas ou perturbadas de baixas altitudes a submontanhosas, assim como em clareiras, árvores isoladas e em formações vegetais abertas; é uma epífita xerotolerante (Gradstein \& Costa 2003, Gradstein \& Ilkiu-Borges 2009). Na Ilha do Combu, ocorreu sobre cipó e tronco vivo ou em decomposição.

Distribuição no Brasil: AC, AL, AM. AP, BA, CE, DF, ES, GO, MG, MS, MT, PA, PB, PE, RJ, RO, RR, $\mathrm{SC}$ e SP.

35. Microlejeunea acutifolia Steph., Hedwigia 35: 113. 1896

Material selecionado: BRASIL. PARÁ: Belém, Ilha do Combu, Várzea, 20-VIII-2008, O.S. Moura et al. 56 (MG).

Ocorre em florestas de baixas altitudes a submontanhosas, na copa ou no subosque, sobre troncos vivos ou folhas (Gradstein \& Ilkiu-Borges 2009). Na Ilha do Combu, ocorreu em cipó e tronco vivo.

Distribuição no Brasil: PA.
36. Microlejeunea epiphylla Bischler in Bischler, Miller \& Bonner, Nova Hedwigia 5: 378. 1963.

Material selecionado: BRASIL. PARÁ: Belém, Ilha do Combu, Várzea, 20-VIII-2008, O.S. Moura et al. 50 (MG).

Ocorre na copa das árvores ou em subosque, em formações florestais ou abertas, até $2.050 \mathrm{~m}$ de altitude, sendo uma típica epífila, mas também pode ocorrer sobre troncos vivos (Gradstein \& Costa 2003). $\mathrm{Na}$ Ilha do Combu, ocorreu sobre tronco vivo ou em decomposição, cipó e folhas.

Distribuição no Brasil: AL, AP, BA, CE, ES, GO, MA, MG, MS, PA, PB, PE, RJ, SE, SP e TO.

37. Rectolejeunea berteroana (Gottsche ex Steph.) A. Evans, Bull. Torrey Bot. Club 33: 12. 1906.

Material selecionado: BRASIL. PARÁ: Belém, Ilha do Combu, Várzea, 20-VIII-2008, O.S. Moura et al. 61 (MG).

Pode ser encontrada nas margens ou no interior de florestas primárias ou secundárias, assim como em árvores isoladas e restingas, sobre tronco vivo ou em decomposição e sobre folhas (Gradstein \& Costa 2003, Gradstein \& Ilkiu-Borges 2009). Na Ilha do Combu, ocorreu em cipó, tronco vivo e tronco morto.

Distribuição no Brasil: AC, AL, AM, AP, BA, ES, PA, PE, PR, RJ, SC e SP.

38. Rectolejeunea emarginuliflora (Gottsche) A. Evans, Bull. Torrey Bot. Club 33: 14: 1906.

Material selecionado: BRASIL. PARÁ: Belém, Ilha do Combu, Várzea, 27-VIII-2008, O.S. Moura et al. 117 (MG).

Ocorre em florestas de baixas altitudes a submontanhosas sobre troncos de árvores vivas (Gradstein \& Costa 2003). Na Ilha do Combu, ocorreu sobre tronco vivo.

Distribuição no Brasil: AM, BA, ES, PA e SP.

39. Stictolejeunea balfourii (Mitt.) E.W. Jones, J. Bryol. 9: 50. 1976.

Material selecionado: BRASIL. PARÁ: Belém, Ilha do Combu, Várzea, 20-VIII-2008, O.S. Moura et al. 58 (MG).

Foi registrada em floresta periodicamente inundada de baixas altitudes (até $400 \mathrm{~m}$ ), sobre troncos vivos, raízes e rochas dentro ou próximo a 
cursos d'água (Gradstein \& Ilkiu-Borges 2009). Na Ilha do Combu, ocorreu sobre tronco vivo ou em decomposição, sobre galho e raiz.

Distribuição no Brasil: No Brasil, foi reportada apenas para o Estado do Acre. Entretanto, no Pará, S. balfourii var. bekkeri Gradstein foi registrada por Lisboa (dados não publicados) na Serra dos Martírios/Andorinhas, no sul do Estado. Portanto, neste trabalho apresenta-se o segundo registro da espécie no Estado. Na Ilha do Combu, foram registradas as duas variedades: S. balfourii var. balfourii e $S$. balfourii var. bekkeri, mas como a diferença entre as mesmas está no perianto e nem todas as amostras continham essa estrutura, preferiu-se fazer referência apenas à espécie.

40. Stictolejeunea squamata (Willd. ex Weber) Schiffn. in Engler \& Prantl, Nat. Pflanzenfam. 1, 3: 131. 1893.

Material selecionado: BRASIL. PARÁ: Belém, Ilha do Combu, Várzea, 20-VIII-2008, O.S. Moura et al. 66 (MG).

Ocorre tanto na copa quanto no subosque de florestas úmidas primárias ou secundárias de baixas altitudes a montanhosas, sobre troncos vivos, lianas e galhos, ocasionalmente sobre folhas, troncos em decomposição e rochas úmidas (Gradstein 1994, Gradstein \& Costa 2003, Gradstein \& Ilkiu-Borges 2009). Na Ilha do Combu, ocorreu sobre cipó e troncos vivos e em decomposição.

Distribuição no Brasil: AC, AL, AM, AP, BA, ES, MA, MG, PA, PE, RJ, RS, SC e SP.

41. Symbiezidium barbiflorum (Lindenb. \& Gottsche) A. Evans, Bull. Torrey Bot. Club 34: 540. 1908.

Material selecionado: BRASIL. PARÁ: Belém, Ilha do Combu, Várzea, 20-VIII-2008, O.S. Moura et al. 55 (MG).

Foi registrada anteriormente em florestas de baixas altitudes a montanhosas ou em formações vegetais abertas, como restingas, crescendo sobre ramos, troncos vivos ou em decomposição e ocasionalmente sobre folhas vivas (Gradstein \& Costa 2003, Gradstein \& Ilkiu-Borges 2009). Na Ilha do Combu, ocorreu sobre tronco vivo e em decomposição.

Distribuição no Brasil: AC, AM, BA, ES, PA, PE, RJ, SC e SP.

\section{PLAGIOCHILACEAE}

42. Plagiochila gymnocalycina (Lehm. \& Lindenb.) Lindenb. in d'Orbigny, Voy. Amer. Mér. 7, Bot. 2: 81. 1839.

Material selecionado: BRASIL. PARÁ: Belém, Ilha do Combu, Várzea, 27-IX-2008, O.S. Moura et al. 280 (MG).

É uma espécie comum que ocorre tanto em formações florestais quanto em vegetação aberta de baixas altitudes a montanhosas, sobre troncos vivos ou em decomposição, ou em rochas (Gradstein \& Costa 2003, Gradstein \& Ilkiu-Borges 2009). Na Ilha do Combu, ocorreu sobre tronco vivo e em decomposição, galhos e raiz.

Distribuição no Brasil: AC, BA, ES, MG, PA, PE, RJ, SC e SP.

43. Plagiochila montagnei Nees, Ann. Sci. Nat., Bot., ser. 2, 5: 53. 1836.

Material selecionado: BRASIL. PARÁ: Belém, Ilha do Combu, Várzea, 27-IX-2008, O.S. Moura et al. 283 (MG).

Ocorre em formações florestais, na copa ou no subosque, ou em vegetação aberta, em baixas altitudes até $1.200 \mathrm{~m}$, sobre troncos vivos ou em decomposição e sobre rochas (Gradstein \& Costa 2003, Gradstein \& Ilkiu-Borges 2009). Na Ilha do Combu, ocorreu sobre tronco vivo e em decomposição.

Distribuição no Brasil: AC, AL, AP, AM, CE, BA, ES, PA, PE, PR, RJ, RS, SC e SP.

\section{RADULACEAE}

44. Radula javanica Gottsche in Gottsche, Lindenberg \& Nees, Syn. Hepat.: 257: 1845.

Material selecionado: BRASIL. PARÁ: Belém, Ilha do Combu, Várzea, 27-VIII-2009, O.S. Moura et al. 282 (MG).

Ocorre em florestas de baixas altitudes a submontanhosas, sobre troncos vivos ou em decomposição, rochas e folhas vivas (Gradstein \& Costa 2003, Gradstein \& Ilkiu-Borges 2009). Na Ilha do Combu, ocorreu sobre troncos vivos ou em decomposição, cipó, raiz e galhos.

Distribuição no Brasil: AC, AM, AP, BA, ES, MG, MS, MT, PA, PE, PR, RJ, RS, SC e SP. 
45. Radula mammosa Spruce, Mem. Torrey Bot. Club 1: 127.1890

Material selecionado: BRASIL. PARÁ: Belém, Ilha do Combu, Várzea, 27-VIII-2008, O.S. Moura et al. 122 (MG).

Ocorre até $1.800 \mathrm{~m}$ de altitude, sobre folhas vivas (Gradstein \& Costa 2003). Na Ilha do Combu, ocorreu exclusivamente sobre folhas.

Distribuição no Brasil: AM, BA, SC, RJ e SP. Esta espécie foi referida pela primeira vez para o Estado do Pará por Tavares (2009), no município de Capitão Poço, sendo este o segundo registro para o Estado.

\section{BRYOPHYTA}

\section{CALYMPERACEAE}

46. Calymperes afzelii Sw., Jahrb. Gewächsk. 1(3): 1. 1818.

Material selecionado: BRASIL. PARÁ: Belém, Ilha do Combu, Várzea, 20-VIII-2008, O. S. Moura et al. 274 (MG).

Ocorre geralmente em florestas de baixas altitudes, sobre tronco vivo e em decomposição, e raramente sobre rochas, preferindo lugares sombreados (Edwards 1980, Lisboa 1993). Na Ilha do Combu, ocorreu sobre tronco vivo e em decomposição.

Distribuição no Brasil: AC, AM, BA, ES, MT, MS, PA, PB, PE, RJ, RO, RR, SC, SP e TO.

47. Calymperes erosum Müll. Hal., Linnaea 21: 182. 1848.

Material selecionado: BRASIL. PARÁ: Belém, Ilha do Combu, Várzea, 27-IX-2008, O.S. Moura et al. 245 (MG).

Cresce em florestas úmidas e em cerrado, sobre tronco vivo ou em decomposição, raramente sobre rochas (Yano \& Peralta 2007b). Na Ilha do Combu, ocorreu sobre raiz viva e tronco em decomposição.

Distribuição no Brasil: AC, AM, AP, BA, ES, GO, MG, MT, PA, PB, PE, RJ, RO, RR e TO.

48. Calymperes lonchophyllum Schwägr., Spec. Musc. Suppl. 1(2): 333, 98. 1816.

Material selecionado: BRASIL. PARÁ: Belém, Ilha do Combu, Várzea, 20-VIII-2008, O.S. Moura et al. 1 (MG).
Apresenta preferência por matas de planícies, podendo ocorrer sobre tronco vivo ou em decomposição, raramente sobre rochas (Florschütz 1964, Lisboa 1993). Na Ilha do Combu, ocorreu apenas sobre tronco vivo.

Distribuição no Brasil: AC, AP, AL, AM, BA, ES, GO, MA, MG, MS, MT, PA, PE, PR, RJ, RO, RR, SP e TO.

49. Calymperes palisotii Schwägr., Spec. Musc. Frond., Suppl. 1(2): 334. 1816.

Material selecionado: BRASIL. PARÁ: Belém, Ilha do Combu, Várzea, 20-VIII-2008, O.S. Moura et al. 6 (MG).

Ocorre com freqüência em florestas tropicais de baixas altitudes, sobre rochas, palmeiras, tronco vivo e em decomposição (Reese 1993). É uma espécie tolerante a ambientes alagados e às altas intensidades de luz e temperatura, ocorrendo em ecossistemas como mangue e pântanos na Austrália (Reese \& Stone 1995). Na Ilha do Combu, ocorreu sobre tronco vivo, em decomposição, cipó, raiz e folhas.

Distribuição no Brasil: AL, AM, AP, BA, CE, ES, FN, GO, MA, MG, MS, MT, PA, PB, PE, PI, PR, RJ, RN, RO, RR, SE, SP e TO.

50. Octoblepharum albidum Hedw., Spec. Musc. Frond.: 50. 1801.

Material selecionado: BRASIL. PARÁ: Belém, Ilha do Combu, Várzea, 27-IX-2008, O.S. Moura et al. 242 (MG).

Ocorre geralmente em florestas úmidas, savanas e em áreas urbanas, sendo típica de terras de baixa altitude (Florschütz 1964). É comum sobre troncos de árvores, principalmente palmeiras (Yano 1982), troncos caídos e sobre o solo. Na Ilha do Combu, ocorreu apenas sobre tronco em decomposição.

Distribuição no Brasil: AC, AL, AM, AP, BA, CE, DF, ES, FN, GO, MA, MG, MS, MT, PA, PB, PE, PI, PR, RJ, RN, RO, RR, RS, SC, SE, SP e TO.

\section{FISSIDENTACEAE}

51. Fissidens guianensis Mont., Ann. Sci. Nat. Bot. Sér. 2, 14: 340. 1840.

Material selecionado: BRASIL. PARÁ: Belém, Ilha do Combu, Várzea, 20-VIII-2008, O.S. Moura et al. 48 (MG). 
Pode ser encontrada em mata de terra firme e mancha de cerrado (savanas) (Lisboa 1993); sobre termiteiro, solo arenoso (Yano 2004), troncos vivos ou em decomposição, rochas e ocasionalmente sobre argila (Florschütz 1964, Yano \& Peralta 2007b). Na Ilha do Combu ocorreu sobre raiz, tronco vivo e em decomposição.

Distribuição no Brasil: AC, AL, AM, BA, ES, GO, MA, MG, MS, MT, PA, PB, PE, PI, RJ, RO, RR, RS, SP e TO.

52. Fissidens hornschuchii Mont., Ann. Sci. Nat. Bot. ser. 2, 40: 342. 1840.

Material selecionado: BRASIL. PARÁ: Belém, Ilha do Combu, Várzea, 20-VIII-2008, O.S. Moura et al. 49 (MG).

Referida para florestas úmidas não inundadas, sobre bases de árvores e rochas (Buck 2003). Contudo na Ilha do Combu, foi coletada em floresta de várzea, sobre tronco vivo e em decomposição.

Distribuição no Brasil: AL, AM, BA, CE, DF, ES, GO, MA, MG, MS, MT, PA, PB, PE, PI, PR, RJ, RO, RS, SC e SP.

53. Fissidens pellucidus Hornschuch, Linnaea 15: 146. 1841.

Material selecionado: BRASIL. PARÁ: Belém, Ilha do Combu, Várzea, 20-VIII-2008, O.S. Moura et al. 32 (MG).

Pode ser encontrada em florestas úmidas, savanas, florestas de terra firme, mata de várzea e capoeiras, sobre rocha, troncos em decomposição, termiteiros, solos e raízes de palmeiras (Lisboa 1993, Souza \& Lisboa 2006). Na Ilha do Combu, ocorreu sobre tronco vivo e em decomposição.

Distribuição no Brasil: AC, AM, BA, CE, DF, ES, GO, MG, MT, PA, PB, PE, PR, RJ, RO, RR, RS, SC, SP e TO.

\section{HYPNACEAE}

54. Isopterygium subbrevisetum (Hampe) Broth., Nat. Pfl. Fam. 1(3): 1081. 1908.

Material selecionado: BRASIL. PARÁ: Belém, Ilha do Combu, Várzea, 20-VIII-2008, O.S. Moura et al. 32 (MG).
Pode ser encontrada em florestas úmidas, sobre troncos de árvores vivas e em decomposição, solo e, raramente, sobre rochas (Florschütz-de Waard \& Veling 1996). Na Ilha do Combu, ocorreu sobre tronco vivo e em decomposição.

Distribuição no Brasil: AC, AM, AP, BA, CE, MG, PA, RJ, RO, SC e SP.

55. Isopterygium tenerum (Sw.) Mitt., J. Linn. Soc. Bot. 12: 499. 1869

Material selecionado: BRASIL. PARÁ: Belém, Ilha do Combu, Várzea, 20-VIII-2008, O.S. Moura et al. 25 (MG).

Essa espécie é extremamente variável em tamanho e hábito (Sharp et al. 1994), sendo considerada de difícil identificação (Behar et al. 1992). Trata-se de uma espécie polimórfica e, devido a essa variabilidade, um grande número de táxons foi sinonimizado com I. tenerum, sendo estes citados por Ireland (1992).

Pode ser encontrada em todo tipo de vegetação, preferencialmente em ambientes bem iluminados e úmidos (Florschütz-de Waard \& Verling 1996), sobre troncos vivos e em decomposição e, raramente, sobre rochas (Sharp et al. 1994). Na Ilha do Combu, ocorreu sobre cipó, raiz, tronco vivo e em decomposição.

Distribuição no Brasil: AC, AM, AP, BA, CE, DF, ES, GO, MA, MG, MS, MT, PA, PB, PE, PI, PR, RJ, RO, RR, RS, SC, SP e TO.

56. Vesicularia vesicularis (Schwägr.) Broth. in Engler \& Prantl, Nat. Pflanzenfam. 1(3): 1094. 1908.

Material selecionado: BRASIL. PARÁ: Belém, Ilha do Combu, Várzea, 27-VIII-2008, O.S. Moura et al. 75 (MG).

Ocorre em florestas úmidas, sobre rochas e tronco vivo ou em decomposição (Buck 1984). Na Ilha do Combu, ocorreu apenas sobre raiz.

Distribuição no Brasil: AC, AM, AP, BA, GO, MG, MS, MT, ES, PA, PE, PI, PR, RJ, RO, RR, RS, SC, SP e TO.

\section{NECKERACEAE}

57. Neckeropsis disticha (Hedw.) Kindb., Canad. Rec. Sci. 6: 21.1894.

Material selecionado: BRASIL. PARÁ: Belém, Ilha do Combu, Várzea, 20-VIII-2008, O.S. Moura et al. 63 (MG). 
Pode ser encontrada em florestas úmidas, sobre pedras e córtex de árvores vivas ou em decomposição, raramente na base do tronco (Buck 1998). Na Ilha do Combu, ocorreu sobre tronco vivo e em tronco e galhos em decomposição.

Distribuição no Brasil: AC, AM, BA, ES, GO, MG, MS, MT, PA, PE, PR, RJ, RO, RR, RS, SC, SP e TO.

58. Neckeropsis undulata (Hedw.) Reichardt, Verh.

Zool. Bot. Ges. Wien. 18: 192. 1868.

Material selecionado: BRASIL. PARÁ: Belém, Ilha do Combu, Várzea, 20-VIII-2008, O.S. Moura et al. 7 (MG).

Pode ser encontrada em floresta de montana, sobre tronco de árvore viva, frequentemente na base, tronco em decomposição e em rochas (Churchill \& Linares 1995, Buck 1998). Na Ilha do Combu, ocorreu apenas sobre tronco vivo.

Distribuição no Brasil: AC, AL, AM, AP, BA, CE, DF, ES, GO, MA, MG, MS, MT, PA, PE, PR, RJ, RO, RR, RS, SC, SP e TO.

\section{PILOTRICHACEAE}

59. Callicostella pallida (Hornsch.) Ångstr., Öfvers. k. Vet. Ak. Foerh. 33(4): 27. 1876.

Material selecionado: BRASIL. PARÁ: Belém, Ilha do Combu, Várzea, 20-VIII-2008, O.S. Moura et al. 48 (MG).

Pode ser encontrada em restingas e manguezal, sobre tronco vivo e em decomposição, solo, raízes e rochas (Florschütz-de Waard 1986, Yano \& Peralta 2007b). Na Ilha do Combu, ocorreu sobre raiz viva no chão, e tronco vivo e em decomposição.

Distribuição no Brasil: AC, AL, AM, AP, BA, CE, DF, ES, GO, MG, MS, MT, PA, PE, PR, RJ, RO, RR, RS, $\mathrm{SC}, \mathrm{SE}, \mathrm{SP}$ e TO.

60. Crossomitrium epiphyllum (Mitt.) Müll. Hal., Linnaea 38: 613. 1874.

Material selecionado: BRASIL. PARÁ: Belém, Ilha do Combu, Várzea, 27-VIII-2008, O.S. Moura et al. 94 (MG).

Pode ser encontrada em florestas úmidas (Buck 2003) e em florestas de terra baixa a sub-montana (Gradstein et al. 2001). Ocorre sobre galhos e tronco vivo e em decomposição, rochas, e sobre folhas (Buck 1998, 2003, Churchill 1998). Na Ilha do Combu, ocorreu apenas sobre tronco vivo.
Essa espécie está largamente distribuída na América Central, Oeste da Índia e América do Sul: Venezuela, Colômbia, Equador, Peru e Bolívia (Schäfer-Verwimp 1992). Até então, no Brasil, tinha sido reportada apenas para o Estado de São Paulo, sendo esta a primeira ocorrência para o Estado do Pará e região Norte.

61. Crossomitrium patrisiae (Brid.) Müll. Hal., Linnaea 38: 612. 1874.

Material selecionado: BRASIL. PARÁ: Belém, Ilha do Combu, Várzea, 27-VIII-2008, O.S. Moura et al. 96 (MG).

Ocorre em florestas úmidas, mas também em savanas e florestas de pântano, geralmente sobre folhas (Florchütz-de Waard 1986). Na Ilha do Combu, ocorreu sobre galho e tronco vivos, troncos em decomposição e sobre folhas.

Distribuição no Brasil: AC, AM, BA, CE, PA, PE, RJ, RO, RR, SC e SP.

62. Lepidopilum affine Müller Hal., Linnaea 21: 192. 1848.

Material selecionado: BRASIL. PARÁ: Belém, Ilha do Combu, Várzea, 27-VIII-2008, O.S. Moura et al. 129 (MG).

Pode ser encontrada sobre raízes, tronco de árvores e arvoretas (Churchill 1998). Na Ilha do Combu, ocorreu apenas sobre tronco vivo.

Distribuição no Brasil: AC, AM, AP, GO, MG, PE, PR, RS, RJ, SC, SP e TO. Primeira citação para o Estado do Pará.

63. Lepidopilum surinamense C. Müll., Linnaea 21: 193. 1848.

Material selecionado: BRASIL. PARÁ: Belém, Ilha do Combu, Várzea, 27-VIII-2008, O.S. Moura et al. 96 (MG).

Pode ocorrer em florestas úmidas e regiões costeiras, sobre folhas de palmeiras, lianas e tronco vivo (Florschütz-de Waard 1986). Na Ilha do Combu, ocorreu apenas sobre tronco em decomposição.

Distribuição no Brasil: AL, AM, AP, BA, PA, RO, RJ e SP.

64. Pilotrichum evanescens (Müll. Hal.) Crosby, Bryologist 72: 326. 1969.

Material selecionado: BRASIL. PARÁ: Belém, Ilha do Combu, Várzea, 20-VIII-2008, O.S. Moura et al. $56(\mathrm{MG})$. 
Ocorre em florestas tropicais de altas altitudes, sobre tronco vivo, arbustos e folhas (Florschütz-de Waard 1986). Na Ilha do Combu, ocorreu sobre tronco vivo e em decomposição.

Distribuição no Brasil: AM, BA, MG, PA, PE, PR, RJ, RO, RR, SC e SP.

\section{PTEROBRYACEAE}

65. Henicodium geniculatum (Mitt.) W.R. Buck, Bryol. 92: 534. 1989.

Material selecionado: BRASIL. PARÁ: Belém, Ilha do Combu, Várzea, 27-IX-2008, O.S. Moura et al. 263 (MG).

Ocorre em florestas úmidas, sobre tronco de árvores (Buck 2003). Na Ilha do Combu, ocorreu apenas sobre tronco em decomposição.

Distribuição no Brasil: AC, AL, AM, AP, BA, CE, DF, ES, GO, MT, PA, PB, PE, RJ, RO, RR e SP.

\section{SEMATOPHYLLACEAE}

66. Sematophyllum subpinnatum (Brid.) E. Britt., Bryologist 21: 28. 1918.

Material selecionado: BRASIL. PARÁ: Belém, Ilha do Combu, Várzea, 20-VIII-2008, O.S. Moura et al. 18 (MG).

Pode ser encontrada em ambientes úmidos e florestas abertas, sobre tronco vivo ou em decomposição, em palmeiras, raramente sobre solo e rochas (Florschütz-de Waard 1996). Na Ilha do Combu, ocorreu apenas sobre tronco em decomposição.

Distribuição no Brasil: AC, AL, AM, AP, BA, CE, DF, ES, GO, MA, MG, MS, MT, PA, PB, PE, PR, RJ, RO, RR, RS, SC, SP e TO.

67. Taxithelium concavum (Hook.) Spruce ex J. Florsch., Flora of the Guianas, Series C, Bryophytes 1: 418. 1996.

Material selecionado: BRASIL. PARÁ: Belém, Ilha do Combu, Várzea, 27-VIII-2008, O.S. Moura et al. 121 (MG).

Ocorre em florestas temporariamente inundadas, sobre pedras, no solo e sobre tronco em decomposição (Florschütz-de Waard 1996). Na Ilha do Combu, ocorreu apenas sobre tronco em decomposição.

Distribuição no Brasil: Esta espécie foi registrada pela primeira vez para o País por Moraes (2006), sendo, aqui, reportada pela segunda vez para o Estado.
68. Taxithelium planum (Brid.) Mitt., J. Linn. Soc. Bot. 12: 496. 1869.

Material selecionado: BRASIL. PARÁ: Belém, Ilha do Combu, Várzea, 16-IX-2008, O.S. Moura et al. 155 (MG).

Ocorre em ambientes periodicamente inundados (Buck 2003), sobre casca de árvore, toras de madeiras (Magill et al. 1994) e pedras. Na Ilha do Combu, ocorreu sobre raiz, tronco vivo e em decomposição.

Distribuição no Brasil: AC, AL, AM, AP, BA, DF, ES, GO, MA, MG, MS, MT, PA, PB, PE, PR, RJ, RO, RR, SC, SP e TO.

69. Trichosteleum papillosum (Hornsch.) A. Jaeger., Ber. S. Gall. Naturw. Ges. 1876-77: 419. 1878.

Material selecionado: BRASIL. PARÁ: Belém, Ilha do Combu, Várzea, 20-VIII-2008, O.S. Moura et al. 64 (MG).

Ocorre em florestas úmidas, cerrado e savanas (Florschütz-de Waard 1996, Yano \& Peralta 2007b), sobre troncos vivos e em decomposição, ocasionalmente em termiteiro, associada a outras espécies de musgos (Souza \& Lisboa 2006). Na Ilha do Combu, ocorreu sobre raiz, tronco vivo e em decomposição.

Distribuição no Brasil: AC, AM, AP, BA, ES, GO, MG, MT, PA, PE, RJ, RO, RR, SC, SE e SP.

70. Trichosteleum subdemissum (Besch.) A. Jaeger, Ber. St. Gall. Naturw. Ges. 1876-77: 418. 1878.

Material selecionado: BRASIL. PARÁ: Belém, Ilha do Combu, Várzea, 20-VIII-2008, O.S. Moura et al. 48 (MG).

Pode ser encontrada em florestas úmidas, restingas, capoeiras, sobre tronco vivo e em decomposição ou associada a outras espécies de musgos (Florschütz-de Waard 1996). Na Ilha do Combu, ocorreu sobre tronco vivo e em decomposição.

Distribuição no Brasil: AM, BA, DF, GO, MA, MG, MT, PA, PI, RJ, RO, RR, SP e TO.

71. Pelekium involvens (Hedw.) Touw., Journal of the Hattori Botanical Laboratory 90: 203. 2001.

Material selecionado: BRASIL. PARÁ: Belém, Ilha do Combu, Várzea, 27-VIII-2008, O.S. Moura et al. 90 (MG). 
Ocorre em florestas úmidas, sobre tronco em decomposição, solo e em calcário (Buck 1998, 2003). $\mathrm{Na}$ Ilha do Combu, ocorreu sobre tronco vivo e em decomposição.

Distribuição no Brasil: AC, AM, AP, BA, DF, MG, MS, MT, PA, RJ, RO, RR e SP.

72. Pelekium scabrosulum (Mitt.) Touw., Journal of the Hattori Botanical Laboratory 90: 204. 2001.

Material selecionado: BRASIL. PARÁ: Belém, Ilha do Combu, Várzea, 20-VIII-2008, O.S. Moura et al. 51 (MG).

Ocorre em ambientes abertos, sobre tronco vivo e em decomposição (Florschütz-de Waard 1996, Zielman 1996). Na Ilha do Combu, ocorreu sobre tronco vivo e em decomposição.

Distribuição no Brasil: AC, AM, BA, DF, GO, MT, $\mathrm{PA}, \mathrm{RO}$ e RR.

\section{Agradecimentos}

As autoras agradecem à M.Sc. Luciana Priscila da Costa Macedo, à Juliana Ribeiro, à Thifany Mendes Pinto e ao Márcio Viana Pereira, pelo auxílio nas atividades de campo; à M.Sc. Rita de Cássia Pereira dos Santos e à Dra. Regina Célia Lobato Lisboa, pela confirmação de algumas espécies de musgos; à Dra. Maria Elena Reiner-Drehwald, pela identificação de Lejeunea obidensis; ao Dr. Mario Augusto Gonçalves Jardim, coordenador do Projeto Padrões de diversidade florística, de regeneração natural e do potencial aromático em duas Unidades de Conservação do Estado do Pará como subsídios ao Plano de Gestão Ambiental (Edital Universal-MCT/CNPq 15/2007 Processo: 472260/2007-3), pelo apoio logístico e financeiro para realização de parte das coletas; ao $\mathrm{CNPq}$, pela concessão da bolsa de estudo à primeira autora; e aos dois revisores anônimos e ao editor de área, pelas valiosas contribuições para a melhoria do manuscrito.

\section{Literatura Citada}

AMAPÁ. 2000. Zoneamento ecológico economic da area sul do Estado do Amapá - ATLAS. Instituto de Pesquisas Científicas e Tecnólogicas do Estado do Amapá, Macapá.
Anderson, A.B. \& Ioris, E.M. 1992. Valuing the rain forest: economic strategies by small-scale forest extractivists in the Amazon estuary. Human Ecology 20: 337-369.

Anderson, A.B. \& Jardim, M.A.G. 1989. Cost and benefits of floodplain forest management by rural inhabitants in the Amazon Estuary: a case study of açaí palm production. In: J. O. Browder (ed.). Fragile lands of Latin America-Strategies for sustainable development. University of Tulane, Colorado, pp.114-129.

Araújo, A.P., Jordy Filho, S. \& Fonseca, W.N. 1986. A vegetação da Amazônia brasileira. In: Anais do $1^{\circ}$ Simpósio do Trópico Úmido. 1984. Documentos, 36. Empresa Brasileira de Pesquisa Agropecuária, Embrapa Amazônia Oriental, Belém, pp.135-152.

Bastos, C.J.P. 2004. Lejeuneaceae (Marchantiophyta) no Estado da Bahia, Brasil. Tese de Doutorado, Universidade de São Paulo, São Paulo.

Bastos, C.J.P. 2012. Lejeuneaceae. In: R.C. Forzza, A. Costa, B.M.T. Walter, J.R. Pirani, M.P. Morim, L.P. Queiroz, G. Martinelli, A.L. Peixoto, M.A.N. Coelho, J.F.A. Baumgratz, J.R. Stehmann, L.G. Lohmann, M. Hopkins. Lista de Espécies da Flora do Brasil. Jardim Botânico do Rio de Janeiro, Rio de Janeiro. http:// floradobrasil.jbrj.gov.br/2012/FB097436 (acesso em 15.12.2012).

Bastos, C.J.P. \& Yano, O. 2009. O gênero Lejeunea Libert (Lejeuneaceae) no Estado da Bahia, Brasil. Hoehnea 36: 303-320.

Behar, L., Yano, O. \& Vallandro, G.C. 1992. Briófitas da restinga de Setiba, Guarapari, Espírito Santo. Boletim do Museu de Biologia Mello Leitão 1: 25-38.

Bischler, H. 1969. Le genre Leptolejeunea (Spruce) Steph., en Amérique. Nova Hedwigia 17: 265-375.

Brito, E.S. 2011. Riqueza e aspectos ecológicos das briófitas do município de Soure e Cachoeira do Arari, Ilha do Marajó, Pará, Brasil. Dissertação de Mestrado, Universidade Federal Rural da Amazônia/Museu Paraense Emílio Goeldi, Belém.

Brito, E.S. \& Ilkiu-Borges, A.L. 2012. Primeiro registro de Cololejeunea panamensis (Lejeuneaceae) para a América do Sul. Rodriguésia 63: 1-3.

Buck, W.R. 1984. Taxonomic and nomenclatural notes on West Indian Hypnaceae. Brittonia 36: 178-183.

Buck, W.R. 1998. Pleurocarpous mosses of the West Indies. Memoirs of the New York Botanical Garden 82: 1-400.

Buck, W.R. 2003. Guide to the Plants of Central French Guiana. Part 3. Mosses. Memoirs of the New York Botanical Garden 76: 1-167.

Churchill, S.P. 1998. Catalog of Amazonian Mosses. Journal of the Hattori Botanical Laboratory 85: 191-238.

Churchill, S.P. \& Linares, C.E.L. 1995. Prodomus Bryologiae Novo-Granatensis: Introducción a la Flora de Musgos de Colombia. Instituto de Ciências Naturales, Museu de História, Faculdade de Ciências, Universidad Nacional de Colômbia, Santafé. 
Cornelissen, J.H.C. \& ter Steege, H. 1989. Distribution and ecology epiphytic bryophytes and lichens in dry evergreen forest of Guyana. Journal Tropical Ecology 5: $131-150$.

Crandall-Stotler, B., Stotler, R.E. \& Long, D.G. 2009. Morphology and classification of Marchantiophyta. In: B. Goffinet \& A.J. Shaw (eds.). Bryophyte Biology. Cambridge University Press, Cambridge, pp. 1-54.

Dauphin, G. 2003. Ceratolejeunea (Lejeuneaceae: Lejeuneoideae). Flora Neotropica Monograph 90: 1-86.

Edwards, S.R.A. 1980. Revision of West Tropical African Calymperaceae. I. Introduction and Calymperes. Journal of Bryology 11: 49-93.

Florschütz, P.A. 1964. The Mosses of Suriname. Part I. In: J. Lanjouw (ed.). Flora of Suriname. E. J. Brill, Leiden, pp.1-271.

Florschütz-de Waard, J. 1986. Musci. Part II. In: A.L. Stoflers \& J.C. Lindeman (eds.). Flora of Suriname. E. J. Brill, Leiden, v.6, pp. 1-361.

Florschütz-de-Waard, J. 1996. Sematophyllaceae. In: A.R.A. Görts-van Rijn (ed.). Flora of the Guianas. Series C: Bryophytes. Musci III. Royal Botanical Gardens, Kew, v.1, pp. 384-438.

Florschütz-de-Waard, J. \& Veling, K. 1996. Hypnaceae. In: A.R.A. Görts-van Rijn (ed.). Flora of the Guianas. Series C: Bryophytes. Musci III. Royal Botanical Gardens, Kew, v.1, pp. 439-462.

Gepp, A. 1891. Musci \& Hepaticae. In: H.N. Ridley (ed.). Notes on the botany of Fernando de Noronha. Journal of the Linnean Society of London, Botany 27: 74-75.

Goffinet, B., Buck W.R. \& Shaw A.J. 2009. Morphology and classification of the Bryophyta. In: B. Goffinet \& A.J. Shaw (eds.). Bryophyte Biology. Cambridge University Press, Cambridge, pp. 55-138.

Gradstein, S.R. 1994. Lejeuneaceae: Ptychantheae, Brachiolejeunea. Flora Neotropica Monograph 62: 1-216.

Gradstein, S.R. \& Costa, D.P. 2003. The Hepaticae and Anthocerotae of Brazil. Memoirs of the New York Botanical Garden 87: 1-196.

Gradstein, S.R. \& Ilkiu-Borges, A.L. 2009. Guide to the plants of Central French Guiana. Part 4. Liverworts and Hornworts. Memoirs of the New York Botanical Garden 76: 1-140.

Gradstein, S.R. \& Pócs, T. 1989. Bryophytes. In: H. Lieth \& M.J.A. Werger (eds.). Tropical Rain Forest Ecosystems. Elsevier Science Publishers, Amsterdam, pp. 311-325.

Gradstein, S.R., Churchill, S.P. \& Salazar-Allen, A. 2001. Guide to the Bryophytes of Tropical America. Memoirs of the New York Botanical Garden 86: 1-577.

Gregório, A.M.S. 2008. Contribuição à Gestão Ambiental da Baía de Guajará (Belém-Pará-Amazônia) através de estudos batimétricos e sedimentalógicos. Dissertação de Mestrado, Universidade Federal do Rio Grande do Sul, Porto Alegre.
Grolle, R. \& Reiner-Drehwald, M.E. 1997. Cheilolejeunea oncophylla (Ångstr.) Grolle \& Reiner comb. nov. (Lejeuneaceae) from the neotropics. Journal of Bryology 19: 781-785.

Ilkiu-Borges, A.L \& Lisboa, R.C.L. 2002. Lejeuneaceae (Hepaticae). In: P.L.B. Lisboa (org.). Caxiuanã: Populações Tradicionais, Meio Físico e Diversidade Biológica. Museu Paraense Emílio Goeldi, Belém, pp. 399-419.

Ilkiu-Borges, A.L. \& Lisboa, R.C.L. 2004. Cololejeuneae (Lejeuneaceae, Hepaticae) na Estação Científica Ferreira Penna, Melgaço, PA, Brasil. Acta Botanica Brasilica 18: 887-902.

Ilkiu-Borges, A.L., Tavares, A.C.C. \& Lisboa, R.C.L. 2004. Briófitas da ilha de Germoplasma, Reservatório de Tucuruí, Pará, Brasil. Acta Botanica Brasilica 18: 691-694.

Ilkiu-Borges, A.L., Santos, R.C.P., Macedo, L.P.C. \& Pereira, M.A.V. 2009. As briófitas da ilha do AlgodoalMaiandeua, Pará. In: M.A.G. Jardim (org.). Diversidade Biológica das Áreas de Proteção Ambiental: Ilhas do Combu e Algodoal-Maiandeua - Pará, Brasil. Museu Paraense Emílio Goeldi, Belém, pp. 227-244.

Ireland, R.R. 1992. The moss genus Isopterygium (Hypnaceae) in Latin America. Tropical Bryology 6: 111-132.

Jardim, M.A.G. \& Vieira, I.C.G. 2001. Composição florística e estrutura de uma floresta da Várzea do estuário amazônico, Ilha do Combu, Estado do Pará, Brasil. Boletim do Museu Paraense Emílio Goeldi, série Botânica 17: 333-354.

Joyce, M.V., Mello, Z.R. \& Yano, O. 2006. Briófitas das Ilhas das Palmas, Guarujá, São Paulo, Brasil. Boletim do Instituto de Botânica 18: 101-109.

Lisboa, R.C.L. 1993. Musgos Acrocárpicos do Estado de Rondônia. Coleção Adolpho Ducke. Museu Paraense Emilio Goeldi, Belém.

Lisboa, R.C.L. \& Maciel, U.N. 1994. Musgos da Ilha de Marajó - I - Afuá (Pará). Boletim do Museu Paraense Emílio Goeldi, série Botânica 10: 43-55.

Lisboa, R.C.L., Lima, M.J. \& Maciel, U.N. 1999. Musgos da Ilha de Marajó - II - Município de Anajás, Pará, Brasil. Acta Amazônica 29: 201-206.

Lisboa, R.C.L., Muniz, A.C.M. \& Maciel, U.N. 1998. Musgos da Ilha de Marajó - III - Chaves (Pará). Boletim do Museu Paraense Emílio Goeldi, série Botânica 14: 117-125.

Lista de Espécies da Flora do Brasil. 2012. In: R.C. Forzza, A. Costa, B.M.T. Walter, J.R. Pirani, M.P. Morim, L.P. Queiroz, G. Martinelli, A.L. Peixoto, M.A.N. Coelho, J.F.A. Baumgratz, J.R. Stehmann, L.G. Lohmann, M. Hopkins. Lista de Espécies da Flora do Brasil. Jardim Botânico do Rio de Janeiro, Rio de Janeiro. http://floradobrasil.jbrj.gov.br/2012 (acesso em 15.12.2012). 
Magill, R.E., Crum, H.A. \& Buck, W.R. 1994. Sematophyllaceae. In: A.J. Sharp, H. Crum \& P.M. Eckel (eds.). The Moss Flora of México. Memoirs of the New York Botanical Garden 69: 974-1009.

Milliken, W. \& Ratter, J.A. 1989. The vegetation of the ilha de Maracá - First Report of the Vegetation Survey of the Maracá Rainforest Project (INPA/RGS/SEMA). Royal Botanical Garden, Edinburgh.

Moraes, E.N.R. 2006. Diversidade, aspectos florísticos e ecológicos dos musgos (Bryophyta) da estação científica Ferreira Penna, flona de Caxiuanã, Pará, Brasil. Dissertaçãode de Mestrado, Universidade Federal Rural da Amazônia/ Museu Paraense Emílio Goeldi, Pará.

Moura, O.S., Ilkiu-Borges, A.L., Reiner-Drehwald, M.E. 2012. A new species of Lejeunea Lib. (Lejeuneaceae) from Low Várzea Forest in lower Amazon (Pará, Brazil). Nova Hedwigia 95: 197-202.

Oliveira-e-Silva, M.I.M.N. \& Yano, O. 2000. Musgos de Mangaratiba e Angra dos Reis, Rio de Janeiro, Brasil. Boletim do Instituto de Botânica 14: 1-138.

Oliveira-e-Silva, M.I.M.N., Milanez, A.I. \& Yano, O. 2002. Aspectos ecológicos de briófitas em áreas preservadas de mata atlântica, Rio de Janeiro, Brasil. Tropical Bryology 22: 77-102.

Peralta, D.F. \& Yano. O. 2008. Briófitas do Parque Estadual da Ilha Anchieta, Ubatuba, Estado de São Paulo, Brasil. Iheringia, série Botânica 63: 101-127.

Pires, J.M. 1974. Tipos de Vegetação da Amazônia. Brasil Florestal 17: 48-58.

Queiroz, J.A.L., Machado, S.A., Hosokawa, R.T. \& Silva, I.C. 2007. Estrutura e Dinâmica de floresta de Várzea no estuário Amazônico no Estado do Amapá. Floresta 37: 339-352.

Reese, W.D. 1993. Calymperaceae. Flora Neotropica Monograph 58:1-102.

Reese, W.D. \& Stone, I.G. 1995. The Calymperaceae of Australia. Journal of the Hattori Botanical Laboratory 78: $1-40$.

Reiner-Drehwald, M.E. 2000. Las Lejeuneaceae (Hepaticae) de Misiones, Argentina VI. Lejeunea y Taxilejeunea. Tropical Bryology 19: 81-131.

Reiner-Drehwald, M.E. 2007. Preliminary key to the genus Lejeunea in Brazil. In: Revision of the genus Lejeunea for Flora Neotropica. Department of Systematic Botany, Albrecht von Haller Institute of Plant Sciences, University of Göttingen, Göttingen.

Reiner-Drehwald, M.E. 2009. Lejeunea adpressa Nees (Lejeuneaceae) a widely distributed species of tropical America. Cryptogamie, Bryology 30: 329-336.

Reiner-Drehwald, M.E. \& Goda, A. 2000. Revision of the Genus Crossotolejeunea (Lejeuneaceae, Hepaticae). The Journal of the Hattori Botanical Laboratory 89: 1-54.
Reiner-Drehwald, M.E. \& Ilkiu-Borges, A.L. 2007. Lejeunea huctumalcensis, a widely distributed Lejeuneaceae from the Neotropics, and its relation to Ceratolejeunea. The Bryologist 110: 465-474.

Ribeiro, R.N.S., Tourinho, M.M. \& Santana, A.C. 2004. Avaliação da sustentabilidade agroambiental de unidades produtivas agroflorestais em várzeas flúvio marinhas de Cametá - Pará. Acta Amazônica 34: 359-374.

Robbins, R.G. 1952. Bryophyta Ecology of a dune area in New Zealand vegetation. Acta Geobotânica 4:1-131.

Rodrigues, L.M.B., Lira, A.U.S., Santos, F.A. \& Jardim, M.A.G. 2006. Composição florística e usos das espécies vegetais de dois ambientes de florestas de Várzea. Revista Brasileira de Farmácia 87: 45-48.

Schäfer-Verwimp, A. 1992. New or interesting records of Brazilina Bryophytes, III. Journal of the Hattori Botanical Laboratory 71: 55-68.

Schuster, R.M. 1980. The Hepaticae and Anthocerothe of North America. East of the Hundredth Meridian. Columbia University Press, New York.

Sharp, A.J., Crum, H., Eckel, P.M. (eds.). 1994. The moss flora of Mexico. VL. Sphagnales to Bryales. The New York Botanical Garden, New York.

Souza, A.P.S. \& Lisboa, R.C.L. 2005. Musgos (Bryophyta) na Ilha Trambioca, Barcarena, PA. Acta Botanica Brasilica 19: 487-492.

Souza, A.P.S. \& Lisboa, R.C.L. 2006. Aspectos florísticos e taxonômicos dos musgos do município de Barcarena, Pará. Boletim do Museu Paraense Emílio Goeldi, Ciências Naturais 1: 81-104.

Spruce, R. 1884. Hepaticae Amazonicae et Andine. Transactions and Proceedings of the Botanical Society, Edinburg 15: 1-588.

Tan, B.C. \& Pócs, T. 2000. Bryogeography and conservation of bryophytes. In: A.J. Shaw \& B. Goffinet (eds.). Bryophyte Biology, Cambridge University Press, Cambridge, pp. 403-448.

Tavares, A.C.C.T. 2009. Brioflora de florestas de terra firme em diferentes estágios de sucessão no município de Capitão poço, Pará, Brasil. Tese de Doutorado, Instituto de Pesquisa Jardim Botânico do Rio de Janeiro, Rio de Janeiro.

Tixier, P. 1985. Contribution à la connaissance dês Cololejeunoideae. Strauss \& Cramer, Hirschberg.

Van Slageren, M.W.S.J.M. 1985. A taxonomic monograph of the genera Brachiolejeunea and Frullanoides (Hepaticae), with a SEM analysis of the sporophyte in the Ptychanthoideae. Mededeelingen van het Botanisch Museum em Herbarium van de Rijks Universiteit te Utrecht 544: 1-84. 
Visnadi, S.R. \& Vital, D.M. 2001. Briófitas das Ilhas de Alcatrazes, do Bom Abrigo, da Casca e do Castilho, Estado de São Paulo, Brasil. Acta Botanica Brasilica 15: 255-270.

Vital, D.M., Giancotti, C. \& Pursell, R.A. 1991. The bryoflora of Fernando de Noronha, Brasil. Tropical Bryology 4: 23-24.

Yano, O. 1982. Distribuição geográfica de Leucobryaceae (Bryopsida) na Amazônia. Acta Amazônica 12: 307-321.

Yano, O. 1990. Musgos do Parque Estadual da Ilha do Cardoso, Estado de São Paulo: Sphagnaceae, Rhizogoniaceae, Mniaceae, Racopilaceae e Phyllogoniaceae. Anais do II Simpósio de Ecossistemas da Costa Sul e Sudeste Brasileira. Academia de Ciências do Estado de São Paulo, São Paulo, pp. 411-438.

Yano, O. 1992. Briófitas da Ilha de Maracá, Roraima, Brasil. Acta Amazônica 22: 535-539.

Yano, O. 1998. Musgos e Hepáticas. In: R.J.V. Alves (org.). Ilha da Trindade e Arquipelágo Martin Vaz, um ensaio geobotânico. Serviço de documentação da Marinha, Rio de Janeiro.

Yano, O. 2004. Novas ocorrências de briófitas para vários Estados do Brasil. Acta Amazônica 34: 559-576.

Yano, O. 2006. Novas adições ao catálogo de Briófitas brasileiras. Boletim do Instituto de Botânica 17: 1-142.
Yano, O. 2008. Catálago de antóceros e hepáticas brasileiros: literatura original, basiônimo, localidadetipo e distribuição geográfica. Boletim do Instituto de Botânica 19: 1-110.

Yano, O. \& Peralta, D.F. 2007a. Briófitas da Ilha do Bom Abrigo, Estado de São Paulo, Brasil. Hoehnea 34: 87-94.

Yano, O. \& Peralta, D.F. 2007b. Musgos (Bryophyta). In: J.A. Rizzo (org.). Flora dos Estados de Goiás e Tocantins: Criptógamos 1: 1-333.

Yano, O. \& Peralta, D.F. 2008a. Briófitas da Ilhabela, Estado de São Paulo, Brasil. Hoehnea 35: 111-121.

Yano, O. \& Peralta, D.F. 2008b. Antóceros (Anthocerotophyta) e Hepáticas (Marchantiophyta). In: J.A. Rizzo (org.). Flora dos Estados de Goiás e Tocantins: Criptógamos, pp. 1-110.

Yano, O., Mello, Z.R. \& Colletes, A.G. 2003. Briófitas da Ilha Uburuqueçaba, Santos, São Paulo, Brasil. Iheringia, série Botânica 58: 198-214.

Zartman, C.E. \& Ilkiu-Borges, A.L. 2007. Guide to the Epiphyllous Bryophytes of Central Amazonia. Instituto Nacional de Pesquisas da Amazônia, Manaus.

Zielman, H.R. 1996. Thuidiaceae. Musci III. In: A.R.A. Görts-Van Rijn (ed.). Flora of the Guianas. Series C: Bryophytes 1: 371-383. 
